\title{
The spatial distribution and annual cycle of upper ocean thermohaline structure
}

\author{
Sylvia T. Cole ${ }^{1,2}$ and Daniel L. Rudnick ${ }^{1}$ \\ Received 3 February 2011; revised 14 December 2011; accepted 16 December 2011; published 18 February 2012.
}

[1] Observations of the spatial distribution and persistence of thermohaline structure are presented, and show how advection and diffusion affect a passive tracer. More than two years of underwater glider observations in the central subtropical North Pacific showed thermohaline variability over horizontal scales from 5 to $1300 \mathrm{~km}$. Thermohaline fluctuations along isopycnals (spice fluctuations) were elevated in layers throughout the water column with the largest fluctuations near the surface and subtropical frontal regions. Fluctuations were uncorrelated between the layers but stirred by the same velocity field. Spice variance had local extrema in the vertical because of differences in source water properties and the influence of neighboring water masses. Spice variance spanned about three orders of magnitude along deeper isopycnals with larger variance where different water masses met and where velocity and vorticity variance were elevated. Horizontal wave number spectra of spice had slopes of -2 everywhere in the upper $1000 \mathrm{~m}$. Submesoscale spice fluctuations had slopes in physical space near the ratio of the Coriolis parameter to the buoyancy frequency $(f / N)$, consistent with predictions of quasi-geostrophic theory. In the mixed layer, thermohaline structure had a significant annual cycle with smaller interannual differences. Thermohaline fluctuations left behind during restratification and isolated from the mixed layer decayed with time because of diffusion along isopycnals. Horizontal diffusivity estimates in the remnant mixed layer were $0.4 \mathrm{~m}^{2} \mathrm{~s}^{-1}$ at $15-28 \mathrm{~km}$ wavelengths and $0.9 \mathrm{~m}^{2} \mathrm{~s}^{-1}$ at $35-45 \mathrm{~km}$ wavelengths.

Citation: Cole, S. T., and D. L. Rudnick (2012), The spatial distribution and annual cycle of upper ocean thermohaline structure, J. Geophys. Res., 117, C02027, doi:10.1029/2011JC007033.

\section{Introduction}

[2] Horizontal thermohaline structure reflects the dominant processes in the upper ocean. On density surfaces, temperature and salinity fluctuations vary from hot and salty to cold and fresh, so they have been referred to as spice [Veronis, 1972; Munk, 1981]. Spice fluctuations are set at the surface, transferred to isopycnals during restratification, and advected throughout the ocean. Once subducted, spice is a passive tracer. At the largest scales, thermohaline structure has long been used as a tracer to infer basin-scale circulation by tracking extrema in temperature or salinity [e.g., Reid, 1973, 1997]. At mesoscales and submesoscales, features such as fronts [Roden, 1974, 1991], eddies [Lilly et al., 1999; Ladd et al., 2007], and intrusions [Grego, 1980; Shcherbina et al., 2010] can have distinct thermohaline characteristics. This paper addresses the statistics of thermohaline structure from all such features.

[3] We present observations over 5-1300 km scales that include a portion of the cascade of tracer variance from large

\footnotetext{
${ }^{1}$ Scripps Institution of Oceanography, University of California, San Diego, La Jolla, California, USA.

${ }^{2}$ Now at Woods Hole Oceanographic Institution, Woods Hole, Massachusetts, USA.

Copyright 2012 by the American Geophysical Union. 0148-0227/12/2011JC007033
}

to small scales. A tracer such as spice has large-scale gradients that are stretched and folded by mesoscale currents and eddies, effectively stirring the larger-scale field. Mesoscale gradients are stretched and folded by submesoscale features, and so on until the cascade ends at scales where molecular mixing occurs. So the magnitude of spice fluctuations depends on the history of advection and diffusion, with advection stretching and folding existing gradients and transferring variance toward smaller scales. Neither our observations, nor models of ocean circulation, extend to the dissipative scale. So, we require an equation describing tracer and velocity fields that have been averaged over some time and space scales, typically the smallest scales resolved. If Reynolds fluxes that result from the correlation of tracer and velocity at scales smaller than those defining the average are parameterized using effective horizontal and diapycnal diffusivities, $\kappa_{\mathrm{h}}$ and $\kappa_{\rho}$ respectively, the following equation is obtained:

$$
\frac{\partial S_{\text {iso }}}{\partial t}+\mathbf{u} \cdot \nabla S_{\text {iso }}=\kappa_{h}\left(\frac{\partial^{2} S_{\text {iso }}}{\partial x^{2}}+\frac{\partial^{2} S_{\text {iso }}}{\partial y^{2}}\right)+\kappa_{\rho}\left(\frac{\partial^{2} S_{\text {iso }}}{\partial z^{2}}\right),
$$

where $S_{\text {iso }}$ refers to salinity fluctuations on an isopycnal surface, and represents the tracer spice. Thus, gradients in (1) are relative to the isopycnal surface. To make clear how we will use terms relating to the cascade, we offer the following 


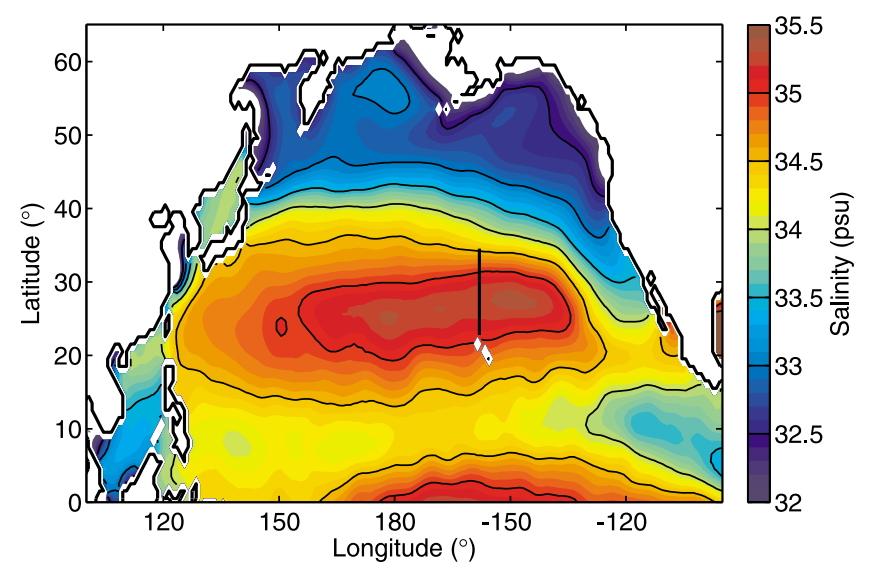

Figure 1. Mean surface salinity from World Ocean Atlas 2005 [Antonov et al., 2006]. The glider track, $22.75-34.5^{\circ} \mathrm{N}$, $158^{\circ} \mathrm{W}$, is shown in black.

definitions. We use the term stirring to refer to advection, $\mathbf{u} \cdot \nabla S_{i s o}$, which tends to increase gradients. Diapycnal mixing, $\kappa_{\rho} \partial^{2} S_{i s o} / \partial z^{2}$, refers to unresolved processes that smooth diapycnal gradients, such as molecular mixing and internal wave breaking. Diffusion, $\kappa_{h}\left[\partial^{2} S_{i s o} / \partial x^{2}+\partial^{2} S_{i s o} / \partial y^{2}\right]$, alludes to along-isopycnal smoothing from unresolved stirring and molecular mixing. Our intention is to use these terms describing parts of the cascade consistently throughout the paper. The goal of this paper is to show how the initial surface conditions, advection, diffusion, and diapycnal mixing generate and modify thermohaline structure.

[4] The large- to small-scale cascade determines the spatial distribution of thermohaline structure. A simple spatial distribution would be large spice fluctuations near the surface with increasingly smaller fluctuations below as water ages, diffuses, and subducts deeper. The observations presented here show that spice fluctuations do not simply decay with depth but are organized into persistent layers. In addition to presenting these observations, we determine which of the processes in (1) caused the layered distribution of spice fluctuations.

[5] Like many tracers, thermohaline structure is set at the surface where it has a significant annual cycle. Annual cycles of heat flux, salt flux, and mixed layer depth [Moisan and Niiler, 1998; Ohno et al., 2009; Bingham et al., 2010] can create, destroy, or modify thermohaline fluctuations in the mixed layer. In and below the mixed layer, annual cycles of currents and eddies [Stammer and Wunsch, 1999; Scharffenberg and Stammer, 2010] cause annual cycles in advection and diffusion that affect existing thermohaline fluctuations. The annual cycle of upper ocean thermohaline structure reflects how a tracer is set by atmospheric forcing and affected by advection and diffusion.

[6] The spatial and temporal variability of thermohaline structure is observed using autonomous gliders, which can sample to $1000 \mathrm{~m}$ depth with $5 \mathrm{~km}$ horizontal resolution over periods from months to years. Fine-scale $(1-10 \mathrm{~km})$ observations have traditionally been made from ships, with logistical constraints limiting repeat observations to a few times per year at most [Weller, 1991; Strass et al., 1992; Joyce et al., 1998; Rudnick and Ferrari, 1999; Ferrari and Rudnick, 2000; James et al., 2002; Cole et al., 2010]. The promise of gliders is sustained fine spatial resolution (examples of sustained glider observations include Davis et al. [2008], Perry et al. [2008], Castelao et al. [2010], and Todd et al. [2011]). We present 2.5 years of glider observations from a $1300 \mathrm{~km}$ line north of Hawaii, representing conditions in the middle of a subtropical gyre.

[7] Because of the glider's $5 \mathrm{~km}$ horizontal resolution, submesoscale thermohaline structure is resolved. We use the term submesoscale to refer to scales less than the Rossby deformation radius [see, e.g., Capet et al., 2008], which is $30-60 \mathrm{~km}$ in the subtropics [Chelton et al., 1998]. Submesoscale features include sharp frontal regions and the edges of eddies or filaments. With improvements in numerical modeling, submesoscale features are becoming important features to parameterize [e.g., Lévy et al., 2010; Fox-Kemper et al., 2011]. The observed submesoscale thermohaline fluctuations give information about advection and diffusion taking place at these scales.

[8] This paper addresses the geography and persistence of thermohaline structure and what it reveals about the history of the water. Observations and methods are described in section 2. The spatial distribution of the spice field is explored in section 3. A short section addressing thermohaline structure on depth surfaces is also included (section 4). Temporal variations in thermohaline structure are described in section 5 , with a focus on the annual cycle. A summary and conclusions are in section 6 .

\section{Observations and Methods}

[9] Observations were taken using Spray underwater gliders [Sherman et al., 2001; Rudnick et al., 2004]. Gliders dove to $1000 \mathrm{~m}$ and measured temperature and salinity with roughly $1 \mathrm{~m}$ vertical resolution during the ascent. Gliders traveled horizontally through the water at about $0.25 \mathrm{~m} \mathrm{~s}^{-1}$. While at the surface between each dive, location was determined using the global positioning system (GPS).

[10] Gliders sampled north of Hawaii along $158^{\circ} \mathrm{W}$ from 22.75 to $34.5^{\circ} \mathrm{N}$ between July 2007 and December 2009 (Figure 1). This glider section began at station ALOHA $\left(22.75^{\circ} \mathrm{N}, 158^{\circ} \mathrm{W}\right)$, a site with monthly observations since 1989 [Karl and Lukas, 1996], and crossed the salinity maximum region in the subtropical gyre. Eight glider deployments, each lasting about 4 months, gave 16 sections of potential temperature $(\theta)$ and salinity (S) (Table 1). The mean \pm standard deviation of the time and distance covered in a dive were $5.8 \pm 0.3 \mathrm{~h}$ and $5.4 \pm 1.1 \mathrm{~km}$. Raw profiles were averaged into $10 \mathrm{~m}$ vertical bins. Properties along isopycnals were calculated by linear interpolation between depth bins. Four deployments did not reach $34.5^{\circ} \mathrm{N}$ for operational reasons including strong opposing currents. Two gliders occupied the line simultaneously in April-May 2008.

[11] The section was observed almost continuously over the 2.5 year time period (Table 1). Sampling was performed to minimize the time between deployments and maximize the length of the section. Observations were collected in all seasons, so an average over all sections is representative of an annual average.

[12] Example salinity sections in winter 2007-2008 and summer 2009 show horizontal and temporal variability (Figure 2). Seasonal changes were evident between sections with a deeper and denser mixed layer in winter. Seasonal or 
Table 1. Glider Deployment Dates and Latitude Range for 3368 Profiles, With Each Deployment Consisting of a Single Northbound Section Followed by a Single Southbound Section

\begin{tabular}{lc}
\hline \multicolumn{1}{c}{ Deployment Dates } & Latitude (deg) \\
\hline 3 Jul 2007 to 8 Sep 2007 & $22.75-30.0$ \\
20 Nov 2007 to 13 Mar 2008 & $22.75-34.5$ \\
5 Apr 2008 to 7 Jul 2008 & $22.75-31.5$ \\
13 Apr 2008 to 3 Jul 2008 & $22.75-30.0$ \\
4 Aug 2008 to 16 Nov 2008 & $22.75-34.5$ \\
9 Dec 2008 to 30 Mar 2009 & $22.75-34.5$ \\
14 Apr 2009 to 9 Aug 2009 & $22.75-34.4$ \\
27 Aug 2009 to 16 Dec 2009 & $22.75-33.1$ \\
\hline
\end{tabular}

interannual changes were seen in surface salinity and its horizontal gradient. Subtropical fronts were apparent as mixed layer salinity gradients concentrated into frontal regions near $25^{\circ} \mathrm{N}$ and $32^{\circ} \mathrm{N}$. Salinity fluctuations occurred throughout the water column on a range of horizontal scales.

[13] An objective map provides an operational separation of mesoscale and larger-scale features from submesoscale features and internal waves. Because gliders profile relatively slowly, taking $5.8 \mathrm{~h}$ to travel $5.4 \mathrm{~km}$, the Nyquist frequency falls within the internal wave band. On depth surfaces, high-frequency internal-wave variability projects vertical gradients into horizontal structure. A comparison of our glider observations with a concurrent SeaSoar transect, which samples at $11 \mathrm{~min}$ and $2.6 \mathrm{~km}$ between profiles, shows that wave numbers higher than about 0.03 cycles $\mathrm{km}^{-1}$ are affected [Rudnick and Cole, 2011]. A $30 \mathrm{~km}$ length scale is chosen for objective maps because it removes aliased internal wave variability from quantities at constant depth. The $30 \mathrm{~km}$ length scale also serves as an operational separation between mesoscales and submesoscales. Mapped fields, denoted as $\tilde{X}$ for any variable $\mathrm{X}$, consist of mesoscale and larger-scale features. Fluctuations from mapped fields, $\boldsymbol{X}^{\prime}=X-\tilde{X}$, include submesoscale features and internal waves. Properties at constant density are unaffected by internal wave heaving and are free from projected high-frequency variability, so along-isopycnal properties can be analyzed for submesoscale features [Rudnick and Cole, 2011].

[14] Gliders measure vertically averaged horizontal velocity, from which geostrophic velocity is referenced. Dead reckoning of glider position provides depth averaged horizontal currents, $u$ and $v$, for each dive. Eastward geostrophic velocity, $\tilde{U}_{g e o}$, is calculated from the objectively mapped density gradient with $u$ providing a reference value [Davis et al., 2008; Todd et al., 2011].

\section{Spatial Distribution of Density Compensated Thermohaline Structure}

\subsection{Layering}

[15] The observed spice fluctuations showed distinct and persistent layers. Spice fluctuations can be represented by either temperature or salinity along isopycnals: $\theta_{\text {iso }}(\mathrm{x}, \mathrm{y}, \rho, \mathrm{t})$ or $\mathrm{S}_{\text {iso }}(\mathrm{x}, \mathrm{y}, \rho, \mathrm{t})$. Isopycnals were calculated using potential density referenced to the surface, and may differ in slope from neutral surfaces [McDougall, 1987] at great depth. This
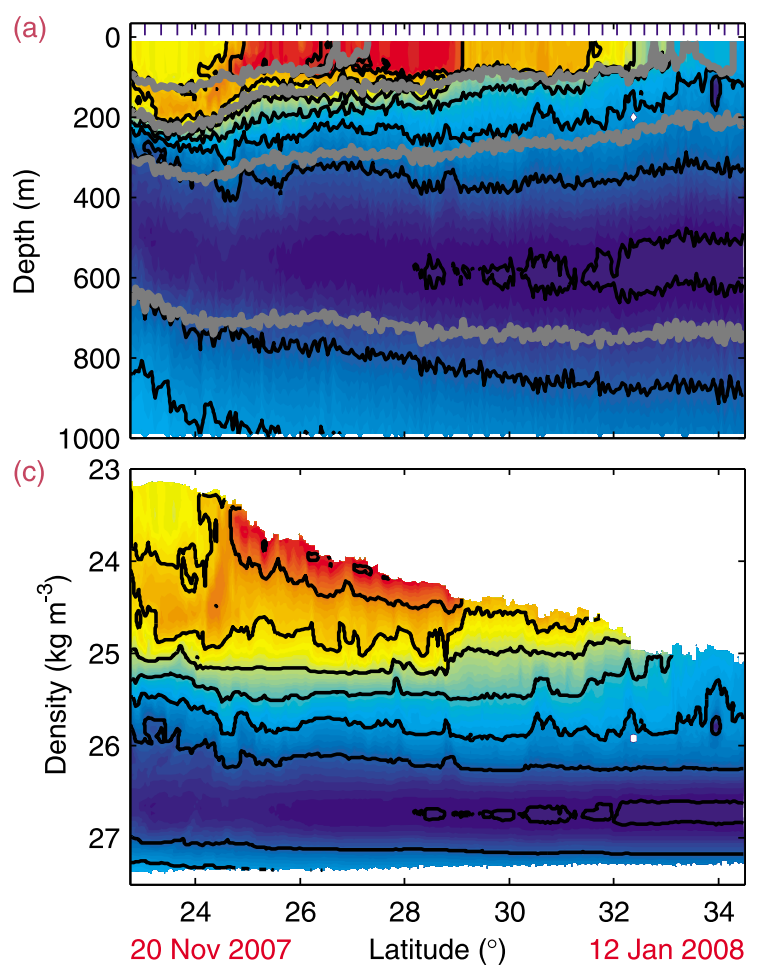

Figure 2. Sections of salinity in (a, c) winter 2007-2008 and (b, d) summer 2009 on depth surfaces (Figures 2a-2b) and on density surfaces (Figures 2c-2d). Depths of the 24.0, 25.0, 26.0, and $27.0 \mathrm{~kg}$ $\mathrm{m}^{-3}$ isopycnals are in gray. The location of every fifth profile is shown as a blue tick mark at the top of the depth sections. Start and end dates for each section are in red.

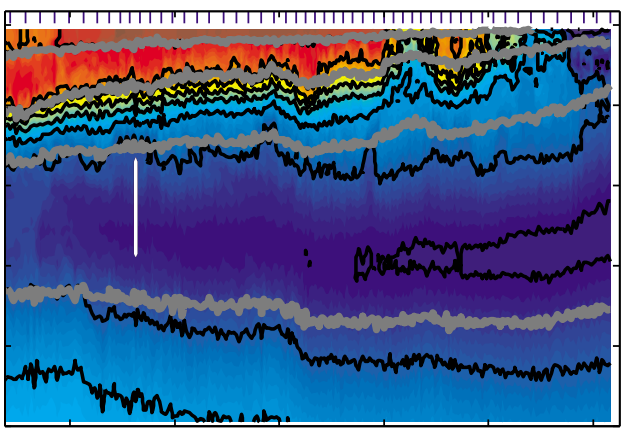

(b)

35.6

35.4

35.2

35

34.8

(d)

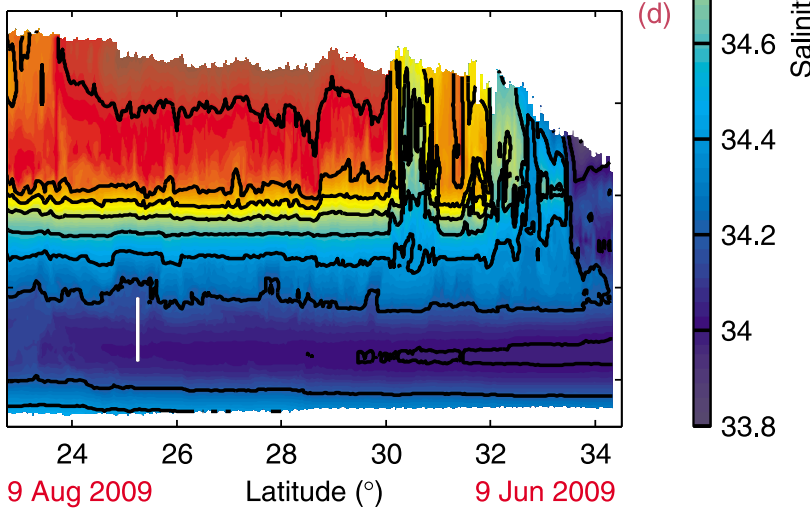



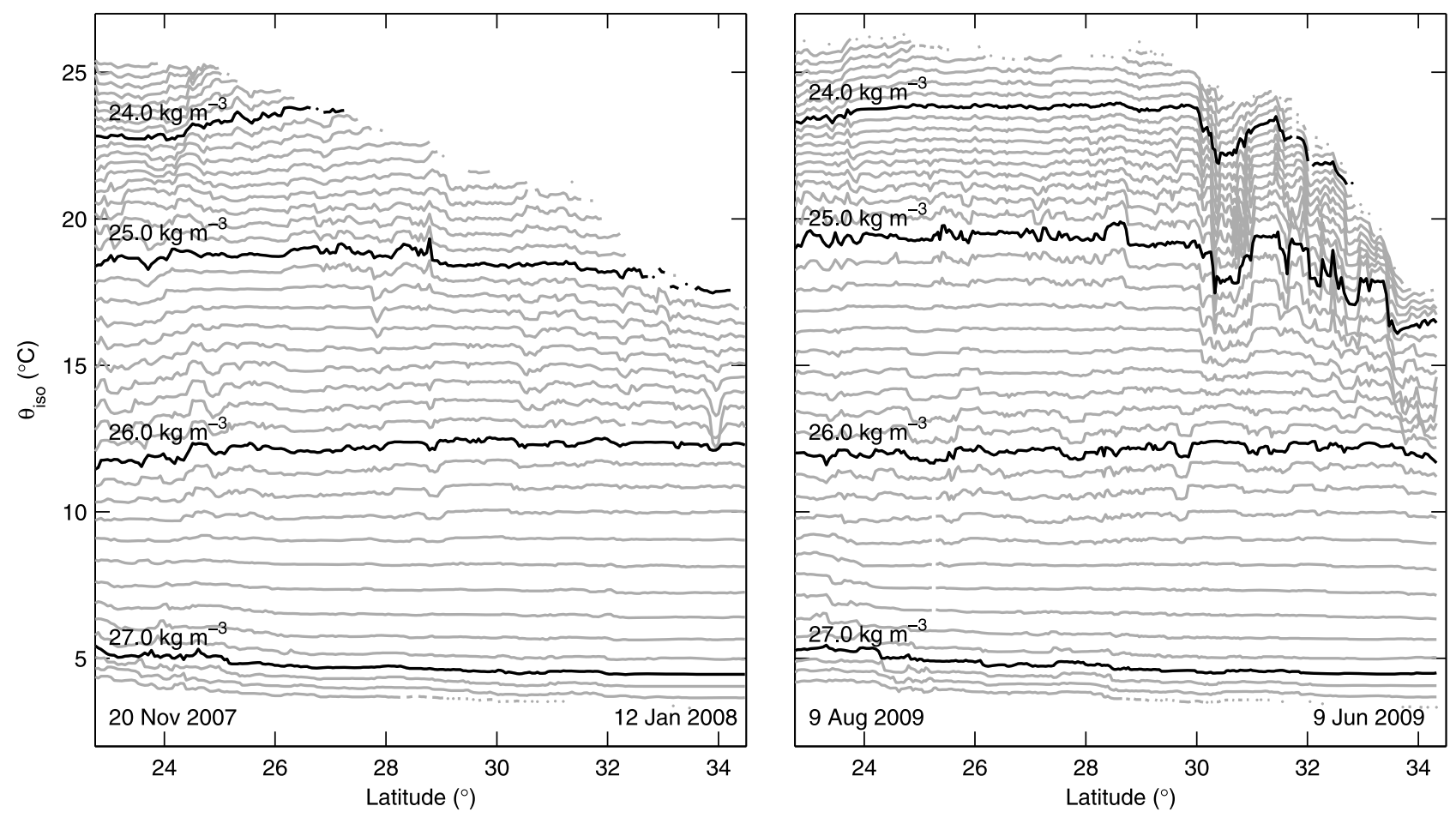

Figure 3. Sections of potential temperature along isopycnals. Isopycnals are spaced apart by $0.1 \mathrm{~kg} \mathrm{~m}^{-3}$ with the $24.0,25.0,26.0$ and $27.0 \mathrm{~kg} \mathrm{~m}^{-3}$ isopycnals in black. Sections are the same as in Figure 2 with start and end dates in the lower corners.

effect was negligible for our observations, which were in the upper $1000 \mathrm{~m}$, as we verified by repeating our calculations referenced to $800 \mathrm{~m}$. In individual sections (Figure 3), three layers with elevated spice fluctuations stood out: the first shallower than $25.0 \mathrm{~kg} \mathrm{~m}^{-3}$, the next near $26.0 \mathrm{~kg} \mathrm{~m}^{-3}$, and the deepest near $27.0 \mathrm{~kg} \mathrm{~m}^{-3}$ south of $28^{\circ} \mathrm{N}$. Regions with small spice fluctuations were located between these layers so that local extrema in spice variance were vertically stacked. The same spatial distribution was observed in all sections, and so was persistent over at least 2.5 years. Locations with large fluctuations can result from several processes (see (1)), including large fluctuations initially subducted, increased stirring velocities, an enhanced gradient available to stir, or weak diffusion. This section focuses on the role of stirring, diffusion, diapycnal mixing, and the thermohaline structure of the subduction region in determining the spatial distribution of spice fluctuations.

[16] Observations over all sections are combined using $30 \mathrm{~km}$ horizontal bins to show the spatial distribution of salinity fluctuations. Each $30 \mathrm{~km}$ bin contains about 5 profiles from each section, and is consistent with the operational separation between mesoscales and submesoscales. Variance at scales larger than $30 \mathrm{~km}$ and one day is calculated by first mapping each $\mathrm{S}_{\text {iso }}$ section (Figures $2 \mathrm{c}$ and $2 \mathrm{~d}$ for example) with a $30 \mathrm{~km}$ length scale, then averaging each section of $\tilde{S}_{\text {iso }}$ in bins, and finally taking the variance over all sections (Figure 4a). Variance at scales less than $30 \mathrm{~km}$ and one day, or submesoscale variance, is calculated by first subtracting $30 \mathrm{~km}$ mapped isopycnal salinity fields from each section, then calculating the variance of $S_{i s o}$ in each bin for each section, and finally averaging this over all sections (Figure 4b). At all observed scales, isopycnal salinity variance had a similar spatial pattern, spanned about four orders of magnitude, and included the vertically stacked layers evident in Figure 3. We divide the discussion into three regions: the region above the winter mixed layer base that is hypothesized to be most related to surface forcing, the upper permanent thermocline with vertically stacked layers of spice variance, and the lower permanent thermocline with horizontally modulated spice variance.

\subsubsection{Remnant Mixed Layer}

[17] Spice fluctuations in the remnant mixed layer, defined as the isopycnals shallower than the winter mixed layer base, are left behind during mixed layer restratification [Cole et al., 2010]. The observed remnant mixed layer had vertically correlated fluctuations (Figure 3 above $25.0 \mathrm{~kg} \mathrm{~m}^{-3}$ for example), and the largest spice variance (Figure 4). Spice variance was horizontally non-uniform, with about an order of magnitude increase in submesoscale variance near the $25^{\circ} \mathrm{N}$ and $32^{\circ} \mathrm{N}$ frontal regions (Figure $4 \mathrm{~b}$ ), because of the enhanced gradient available to stir and the increased variance inherited from the mixed layer.

\subsubsection{Upper Permanent Thermocline}

[18] Three layers of alternating spice variance were observed just below the base of the remnant mixed layer (Figure 4). South of $30^{\circ} \mathrm{N}$, two layers of large variance centered at 25.0 and $25.8 \mathrm{~kg} \mathrm{~m}^{-3}$ surrounded a layer of variance up to an order of magnitude smaller at $25.3 \mathrm{~kg} \mathrm{~m}^{-3}$. All three layers spanned about $300 \mathrm{~m}$ in depth with the middle layer of low variance about $50 \mathrm{~m}$ thick. The winter mixed layer base and uppermost layer increased in density toward the north. North of $30^{\circ} \mathrm{N}$, a single layer of elevated variance encompassed the entire $25.0-26.2 \mathrm{~kg} \mathrm{~m}^{-3}$ density range. This layering was observed in every section (Figure 3 

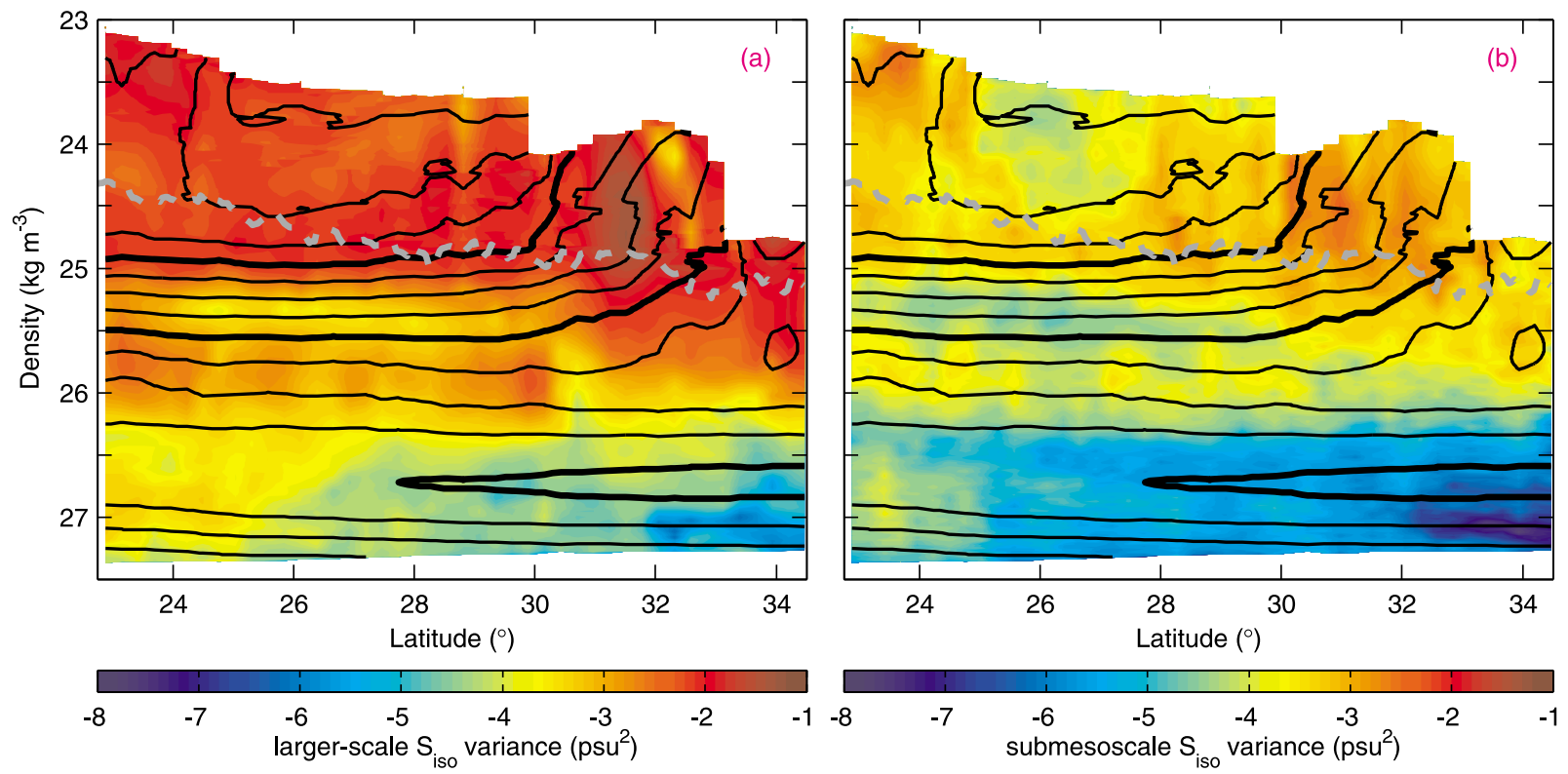

Figure 4. Salinity variance on density surfaces. (a) Variance at scales greater than $30 \mathrm{~km}$ and one day is calculated by first averaging $\tilde{S}_{\text {iso }}$ in $30 \mathrm{~km}$ bins for each section and then taking the variance over all sections. (b) Submesoscale variance at scales less than $30 \mathrm{~km}$ and one day is calculated by first taking the variance of $S_{i s o}^{\prime}$ in $30 \mathrm{~km}$ bins for each section and then averaging over all sections. Variance is shown on a logarithmic scale. Mean salinity contours (black) and the deepest mixed layer base (dashed gray) are shown. Because the minimum density of the mixed layer varied over the year, there were fewer sections in each bin on isopycnals shallower than $25.0 \mathrm{~kg} \mathrm{~m}^{-3}$, and only bins containing at least five sections were considered.

for example) and was persistent over at least 2.5 years. We believe these to be the first observations of persistent submesoscale spice variability in isopycnal layers.

[19] Previous observations show a mid-depth spice variance maximum in the North Atlantic resulted from an enhanced gradient available to $\operatorname{stir}\left(\nabla S_{\text {iso }}\right.$ in (1)) [Ferrari and Polzin, 2005; Smith and Ferrari, 2009]. At $158^{\circ} \mathrm{W}$, World Ocean Atlas 2005 salinity [Antonov et al., 2006; Locarnini et al., 2006] (Figure 5a) agrees well with mean salinity from the glider observations (contours in Figure 4), and so adequately represents the larger-scale salinity field. The $300 \mathrm{~km}$ scale gradient available to stir, $\left(\Delta_{x} S_{i s o}\right)^{2}+\left(\Delta_{y} S_{\text {iso }}\right)^{2}$, was elevated near the surface at the $32^{\circ} \mathrm{N}$ frontal region, near $26.0 \mathrm{~kg} \mathrm{~m}^{-3}$ at $28^{\circ} \mathrm{N}$, and near the southern end of the section on deeper isopycnals (Figure $5 \mathrm{~b}$ ). North of $30^{\circ} \mathrm{N}$, the single layer of spice variance above $26.2 \mathrm{~kg} \mathrm{~m}^{-3}$ (Figure 4) may have resulted from stirring the enhanced large-scale gradient in this region (Figure 5b). South of $30^{\circ} \mathrm{N}$, the large-scale salinity gradient (Figure 5b) had a different spatial distribution from spice variance (Figure 4), so the observed layering in spice variance was not primarily caused by the geography of the gradient available to stir.

[20] We hypothesize that the layers of isopycnal variance had different histories having inherited their initial conditions at different places, or having been stirred by different velocity fields before arriving at the observed section. If this hypothesis is true, spice gradients will be uncorrelated between isopycnal layers. We test the hypothesis through empirical orthogonal functions (EOFs) of isopycnal salinity fluctuations. Submesoscale fluctuations, $S_{i s o}^{\prime}$, were considered over $22.75-30^{\circ} \mathrm{N}$ where three layers of spice variance were observed (Figure 4). The first and second EOFs of $S_{\text {iso }}^{\prime}$ peaked at 25.0 and $25.8 \mathrm{~kg} \mathrm{~m}^{-3}$, respectively, and did not overlap significantly in density (Figure 6a). These peaks coincided with the layers of high variance at 25.0 and $25.8 \mathrm{~kg} \mathrm{~m}^{-3}$ indicating that fluctuations were uncorrelated between the layers. Thus the hypothesis that the layers had different histories is supported.

[21] Distinct tracers stirred by the same velocity field have the property that their gradients are aligned, but not correlated [Ferrari and Paparella, 2003; Hodges and Rudnick, 2006]. That is, large gradients in the tracers tend to occur in the same location, dictated by the strain in the velocity field. However, the sign of the gradients may be from high to low, or low to high, so that the tracers are formally uncorrelated. We test whether spice gradients are aligned using EOFs of the absolute value of isopycnal salinity fluctuations. The first EOF of $\left|S_{i s o}^{\prime}\right|$ explained a majority of the variance and was elevated at all densities (Figure 6b), thus proving that fluctuations were aligned in the vertical. The stirring velocity field was apparently at least thick enough to span both layers of elevated variance. In summary, spice fluctuations in the layers of elevated variance were aligned but not correlated, indicating different histories, but recent stirring by the same velocity field.

[22] Diapycnal mixing may also be important in setting the spatial distribution of spice variance. The relative importance of diapycnal mixing and horizontal stirring is determined by the ratio of $\kappa_{\rho}\left[\left(\partial S_{i s o} / \partial z\right)^{2}\right]$ to $\kappa_{h}\left[\left(\partial S_{i s o} / \partial x\right)^{2}+\left(\partial S_{i s o} / \partial y\right)^{2}\right]$ [Ferrari and Polzin, 2005]. In our observations, horizontal gradients had the layered structure of Figure 4, and vertical gradients decayed with depth from the mixed layer base to 

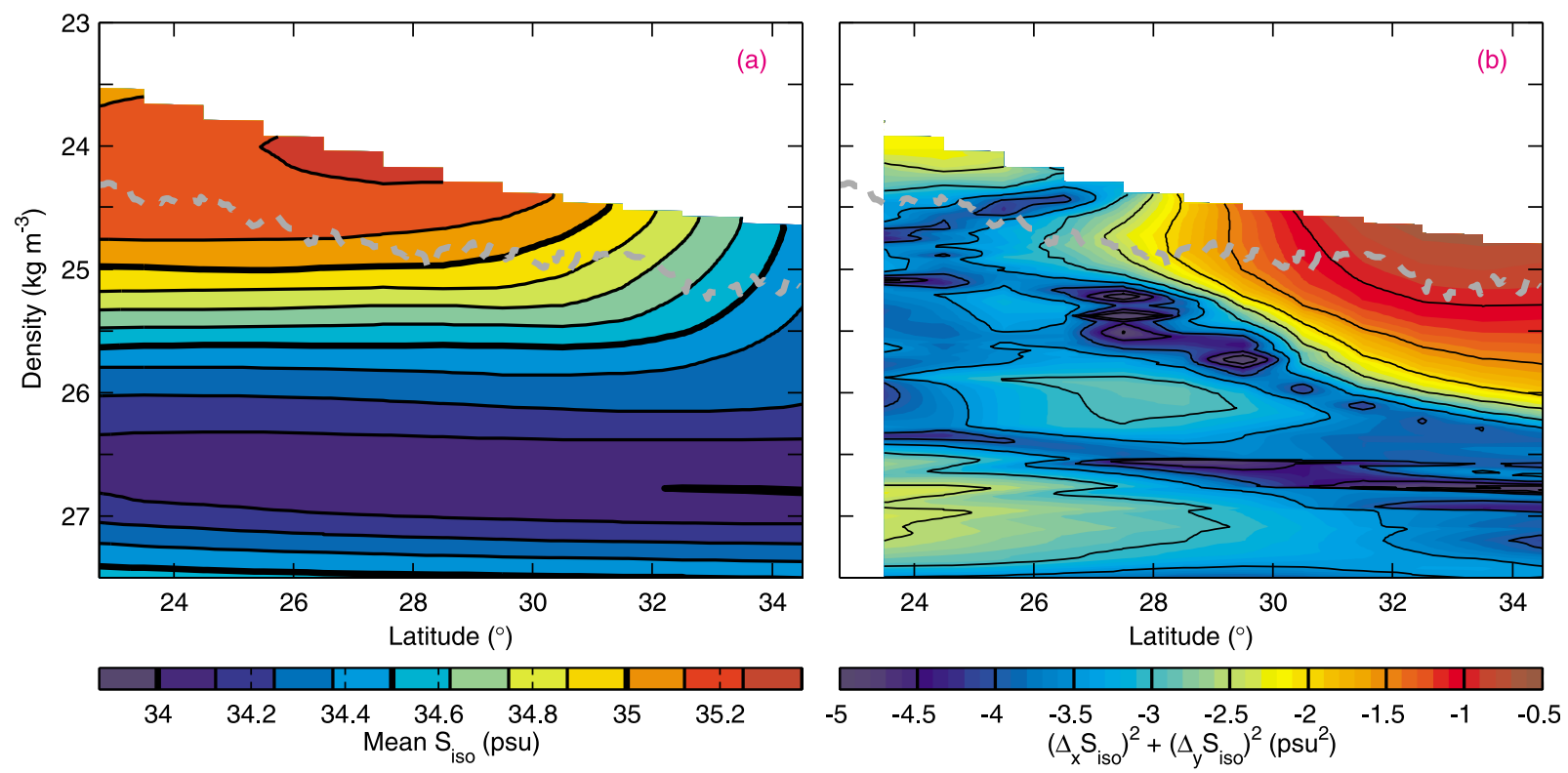

Figure 5. Statistics of salinity along isopycnals at $158^{\circ} \mathrm{W}$ from World Ocean Atlas 2005 [Antonov et al., 2006; Locarnini et al., 2006]. (a) Salinity with the same contouring as in Figure 4. (b) The $300 \mathrm{~km}$ scale gradient of $S_{\text {iso }}$ (shown on a logarithmic scale), which predominately results from the meridional gradient. The deepest mixed layer base from glider observations, as in Figure 4, is shown for reference (dashed gray).

the salinity minimum. So the relative importance of diapycnal mixing in modifying thermohaline structure was largest for the $25.3 \mathrm{~kg} \mathrm{~m}^{-3}$ layer that had small horizontal gradients. In addition, diapycnal mixing between two neighboring layers with uncorrelated fluctuations can generate a third layer in between with smaller variance. For example, consider two layers in which salinity fluctuations are described by random walks. Near the boundary of the two layers, variance is reduced because of diapycnal mixing between the uncorrelated fluctuations. Since the observed spice fluctuations at 25.0 and $25.8 \mathrm{~kg} \mathrm{~m}^{-3}$ were vertically uncorrelated (Figure 6a), diapycnal mixing between these layers may explain the smaller spice variance near $25.3 \mathrm{~kg} \mathrm{~m}^{-3}$.
[23] As spice depends on the history of advection and diffusion, two tracers are considered that give information about the history of the water: dissolved oxygen and the vertical component of potential vorticity, $N_{i s a}^{2} f / g$. Profiles of mean dissolved oxygen and mean percent oxygen saturation are calculated from monthly observations at station ALOHA $\left(22.75^{\circ} \mathrm{N}, 158^{\circ} \mathrm{W}\right)$ [Karl and Lukas, 1996] averaged over 2007-2009 and from a hydrographic section along $152^{\circ} \mathrm{W}$ (http://whpo.ucsd.edu) averaged over $23-29^{\circ} \mathrm{N}$ (Figures $7 \mathrm{a}$ and $7 b$ ). Potential vorticity was calculated from our observations (Figure 7c). Percent saturation shows that water age increased with density in the upper permanent thermocline, and so the low variance at $25.3 \mathrm{~kg} \mathrm{~m}^{-3}$ did not result from
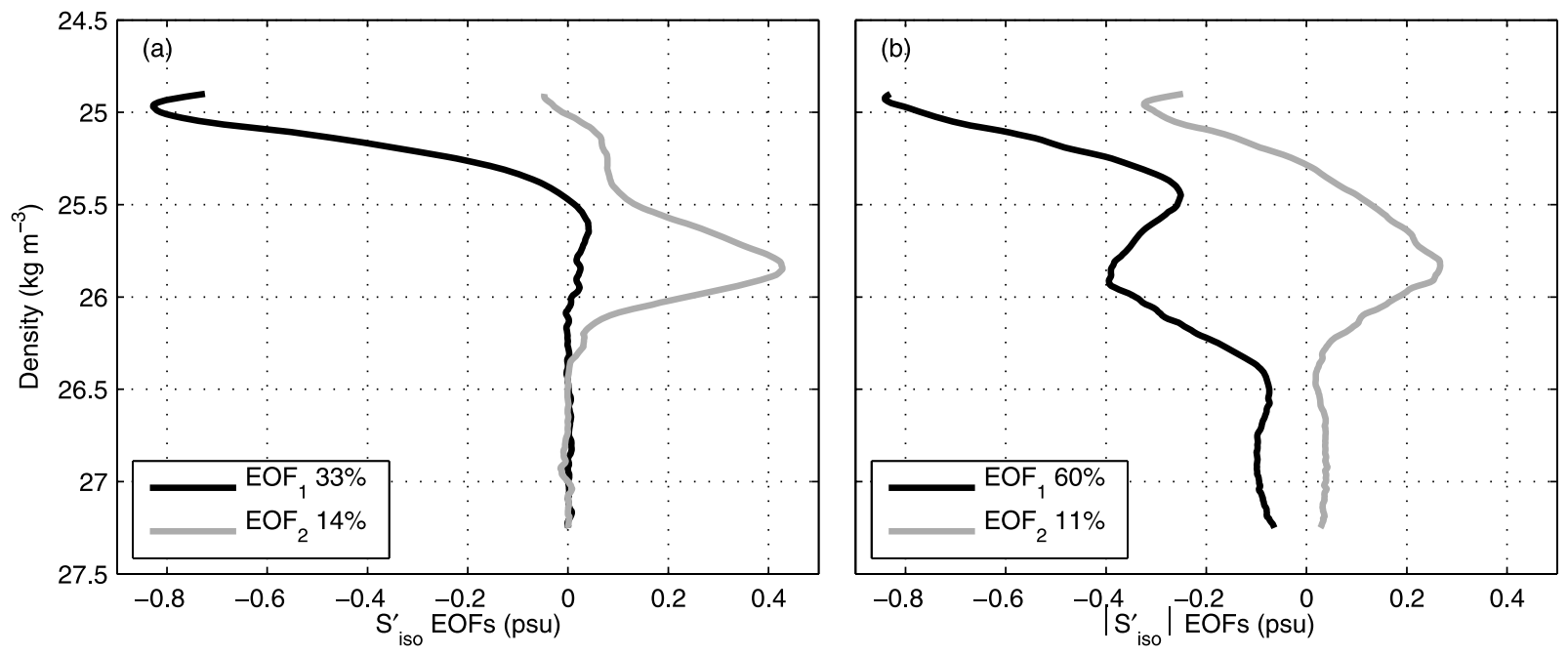

Figure 6. The first two EOFs of (a) $S_{i s o}^{\prime}$ and (b) the absolute value of $S_{i s o}^{\prime}$ over $22.75-30^{\circ} \mathrm{N}$. Fluctuations are considered below the base of the winter mixed layer. The percentage of variance explained by each EOF is in the legend. 

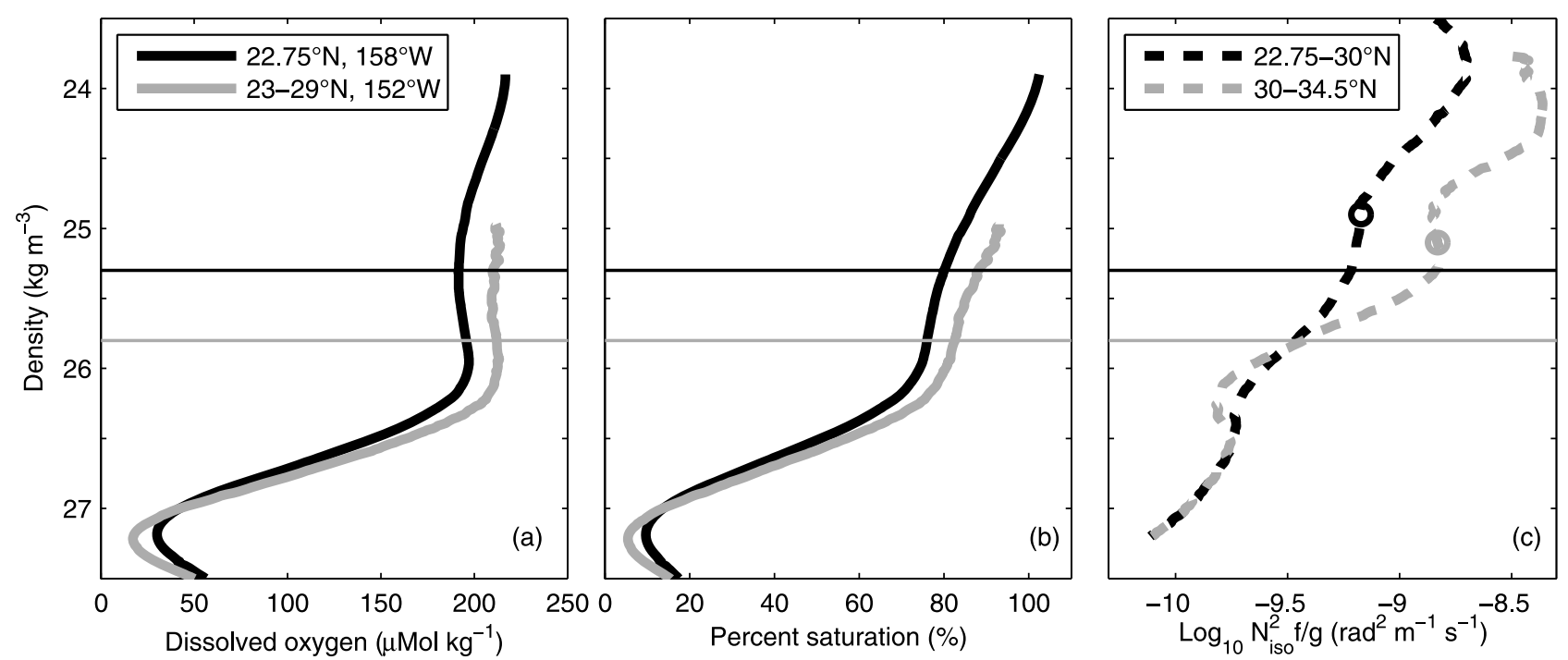

Figure 7. Observations of tracers. (a) Dissolved oxygen and (b) percent saturation of dissolved oxygen from monthly observations at station ALOHA $\left(22.75^{\circ} \mathrm{N}, 158^{\circ} \mathrm{W}\right)$ averaged over $2007-2009$ (black), and from a hydrographic section in March 2006 along $152^{\circ} \mathrm{W}$ averaged over $23-29^{\circ} \mathrm{N}$ (gray). Percent saturation of dissolved oxygen is dissolved oxygen divided by oxygen solubility at the surface at the same potential temperature and salinity. (c) Mean vertical potential vorticity from glider observations over $22.75-30^{\circ} \mathrm{N}$ and $30-34.5^{\circ} \mathrm{N}$. Circles correspond to the deepest observed winter mixed layer base in each region. The $25.3 \mathrm{~kg} \mathrm{~m}^{-3}$ isopycnal (thin black) is a local extremum in stratification, dissolved oxygen, and the curvature of percent saturation. The $25.8 \mathrm{~kg} \mathrm{~m}^{-3}$ isopycnal (thin gray) is a local extremum in the diapycnal gradient of stratification, dissolved oxygen, and percent saturation.

diffusion over a longer time period. Both oxygen and potential vorticity had a layered structure: dissolved oxygen had a local minimum at $25.3 \mathrm{~kg} \mathrm{~m}^{-3}$ and a local maximum just below $25.8 \mathrm{~kg} \mathrm{~m}^{-3}$; percent saturation had a local extremum in curvature at $25.3 \mathrm{~kg} \mathrm{~m}^{-3}$ and changed the least at $25.8 \mathrm{~kg} \mathrm{~m}^{-3}$; potential vorticity had a local maximum at $25.3 \mathrm{~kg} \mathrm{~m}^{-3}$ that was stronger toward the northern end of the section and a local minimum just below $25.8 \mathrm{~kg} \mathrm{~m}^{-3}$. The local maximum in dissolved oxygen and the local minimum in potential vorticity were at $26.2 \mathrm{~kg} \mathrm{~m}^{-3}$, coincident with the base of the $25.8 \mathrm{~kg} \mathrm{~m}^{-3}$ spice variance layer. Oxygen and potential vorticity support the notion that the spice variance layers had different histories.

[24] Differences in spice fluctuations at the subduction region could have caused the observed layering in spice variance. The isopycnal layers identified from spice variance corresponded to distinct water masses further to the north: $24.0-25.4 \mathrm{~kg} \mathrm{~m}^{-3}$ is eastern North Pacific subtropical mode water and $25.5-26.2 \mathrm{~kg} \mathrm{~m}^{-3}$ is shallow salinity minimum water or North Pacific central water [Yuan and Talley, 1992; Hautala and Roemmich, 1998; Suga et al., 2004; Macdonald et al., 2009; Oka et al., 2011]. The distinction in water mass properties suggests that the 25.3 and $25.8 \mathrm{~kg} \mathrm{~m}^{-3}$ layers had different origins with different thermohaline structure. Previous studies have found that water at station ALOHA originates to the north tracing back the gyre circulation toward the Kuroshio extension [Bingham et al., 2002; Stammer et al., 2008; Oka et al., 2011]. It is plausible that the $25.8 \mathrm{~kg} \mathrm{~m}^{-3}$ surface waters near the Kuroshio extension had larger thermohaline fluctuations than the $25.3 \mathrm{~kg} \mathrm{~m}^{-3}$ surface waters closer to the center of the gyre. This initial signal could be observable after subduction and advection to $158^{\circ} \mathrm{W}$, which takes up to
10 years [Warner et al., 1996; Fine et al., 2001; Bullister et al., 2006; Stammer et al., 2008].

[25] In summary, the initial conditions, stirring, and diapycnal mixing influenced the alternating layers of variance in the upper permanent thermocline. Recent stirring by the same velocity field aligned fluctuations across the three layers. The spice field also had a different spatial distribution from the gradient available to stir, and so the observed layering did not result from differences in stirring. Layering resulted from differences in the thermohaline structure initially subducted, with large fluctuations in the two layers of elevated variance and most likely smaller fluctuations in the low variance layer. This region is young enough such that stirring or diffusion has not completely erased the patterns imposed at the surface. Finally, the low variance layer was created or amplified as uncorrelated fluctuations mixed vertically. All of these processes affect larger-scale, mesoscale, and submesoscale fluctuations and have occurred simultaneously.

\subsubsection{Lower Permanent Thermocline}

[26] A single layer of spice variance was observed below $26.2 \mathrm{~kg} \mathrm{~m}^{-3}$ with variance gradually decreasing from south to north by three orders of magnitude (Figure 4). The lower permanent thermocline is a distinct layer: fluctuations were vertically correlated over at least $26.4-27.2 \mathrm{~kg} \mathrm{~m}^{-3}$ (not shown), and were not correlated with the region above (Figure 6a; first two EOFs of $S_{\text {iso }}^{\prime}$ were essentially zero below $26.2 \mathrm{~kg} \mathrm{~m}^{-3}$ ). The increased spice variance near the southern end of the section is associated with increased stirring velocities and an enhanced large-scale gradient available to stir. The enhanced gradient available to stir (Figure $5 \mathrm{~b}$ ) results from the North Pacific Intermediate Water (NPIW) 

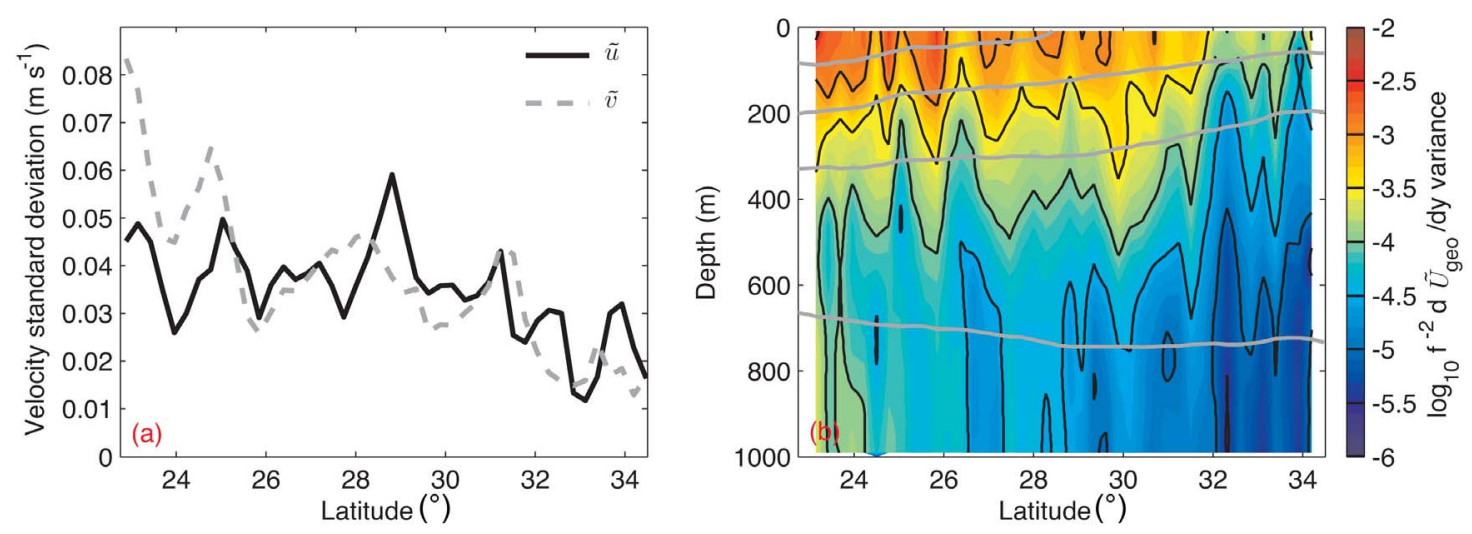

Figure 8. Velocity and vorticity statistics. (a) Standard deviation over all sections of objectively mapped vertically averaged eastward (solid) and northward (dashed) velocity, and (b) variance over all sections of the horizontal gradient of geostrophic velocity. In Figure 8b, gray lines are mean depths of the 24.0, 25.0, 26.0 , and $27.0 \mathrm{~kg} \mathrm{~m}^{-3}$ isopycnals. Only $1000 \mathrm{~m}$ profiles are included in the statistics.

salinity minimum meeting warmer and saltier equatorial waters [Bostock et al., 2010]. Increased stirring velocities are inferred from vertically averaged velocity, $\tilde{u}$ and $\tilde{v}$, and the observed component of geostrophic vorticity, $\partial \tilde{U}_{\text {geo }} / \partial y$, that were least variable near $34.5^{\circ} \mathrm{N}$ with an increase in variability toward the south (Figure 8). An increase in variability toward the south is consistent with previous velocity and dynamic height observations in the region [Talley and DeSzoeke, 1986; Hall et al., 1997; Chen and Qiu, 2010]. The north-south trend in spice variance is inconsistent with a net diffusion, where older water has smaller gradients due to the longer diffusion time, because smaller fluctuations were observed toward the north where NPIW was younger [Talley, 1993; Watanabe et al., 1994]. Along-isopycnal changes in spice variance are also unlikely to result from differences in the initial spice variance subducted. It is the advection term in (1), with both an enhanced gradient available to stir and enhanced stirring velocities that elevated spice variance near $22.75^{\circ} \mathrm{N}$.

\subsection{Wave Number Spectra}

[27] Spectral slopes of a passive tracer reflect the large- to small-scale energy cascade, and have not been previously observed at submesoscale wavelengths below $400 \mathrm{~m}$ depth. Theoretical studies have predicted that passive tracers have

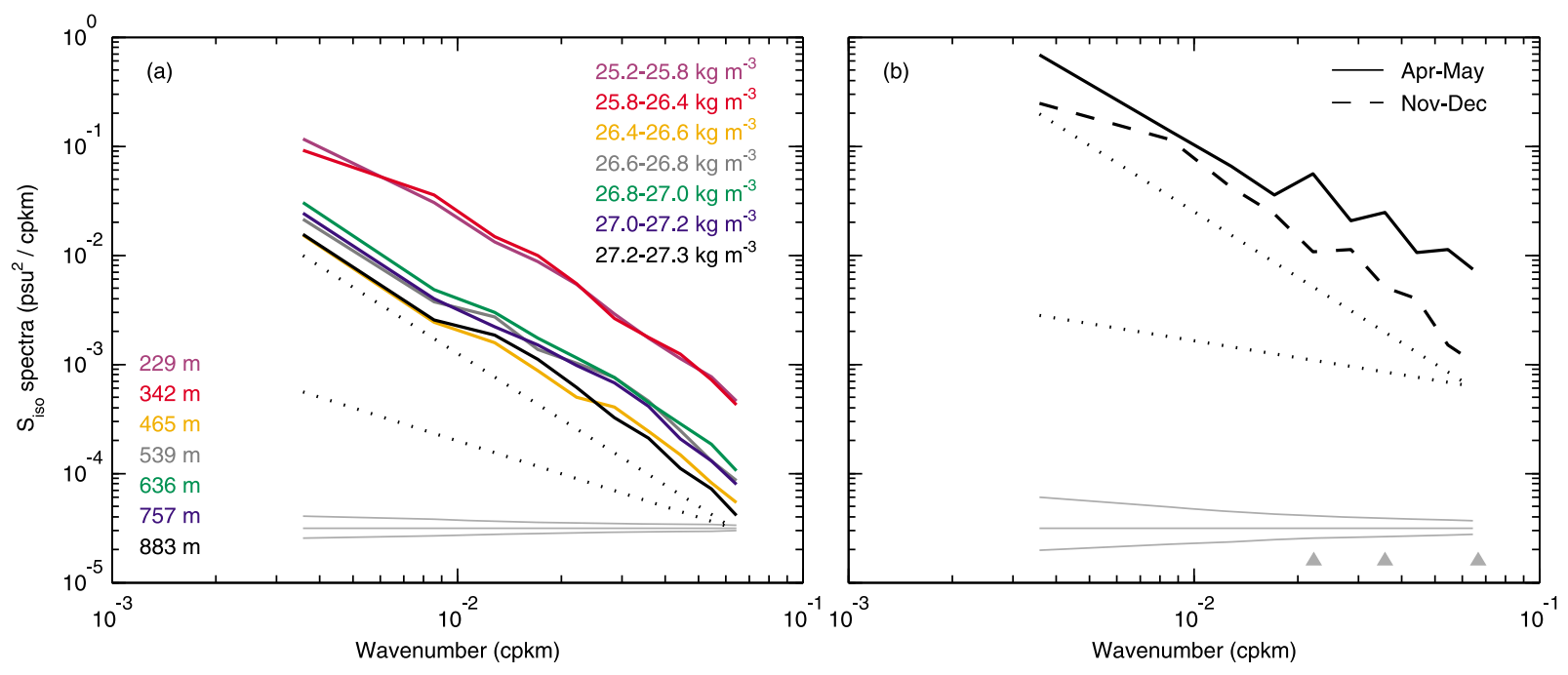

Figure 9. Spectra of salinity along isopycnals over $22.75-29^{\circ}$ N. (a) For different densities in the permanent thermocline. Spectra are averaged over all glider sections and vertically in density bins as indicated (top right corner). The average isopycnal depth of each density bin is also shown (bottom left corner). (b) For different times of the year in the remnant mixed layer. Spectra are averaged over $24.6-24.8 \mathrm{~kg} \mathrm{~m}^{-3}$ and the time periods indicated, which were 215 days apart on average. Apr-May includes 5 Apr to 8 May 2008, 13 Apr to 20 May 2008, and 14 Apr to 15 May 2009 sections, and Nov-Dec includes 20 Oct to 16 Nov 2008, 9 Dec 2008 to 6 Jan 2009, and 12 Nov to 16 Dec 2009 sections. Triangles correspond to 15,28 , and $45 \mathrm{~km}$ wavelengths. Dotted lines show slopes of -1 and -2 . Error bars (light gray) show the $90 \%$ confidence interval. The number of degrees of freedom at each wavelength for each section is taken to be twice the record length, $700 \mathrm{~km}$, divided by the wavelength. 

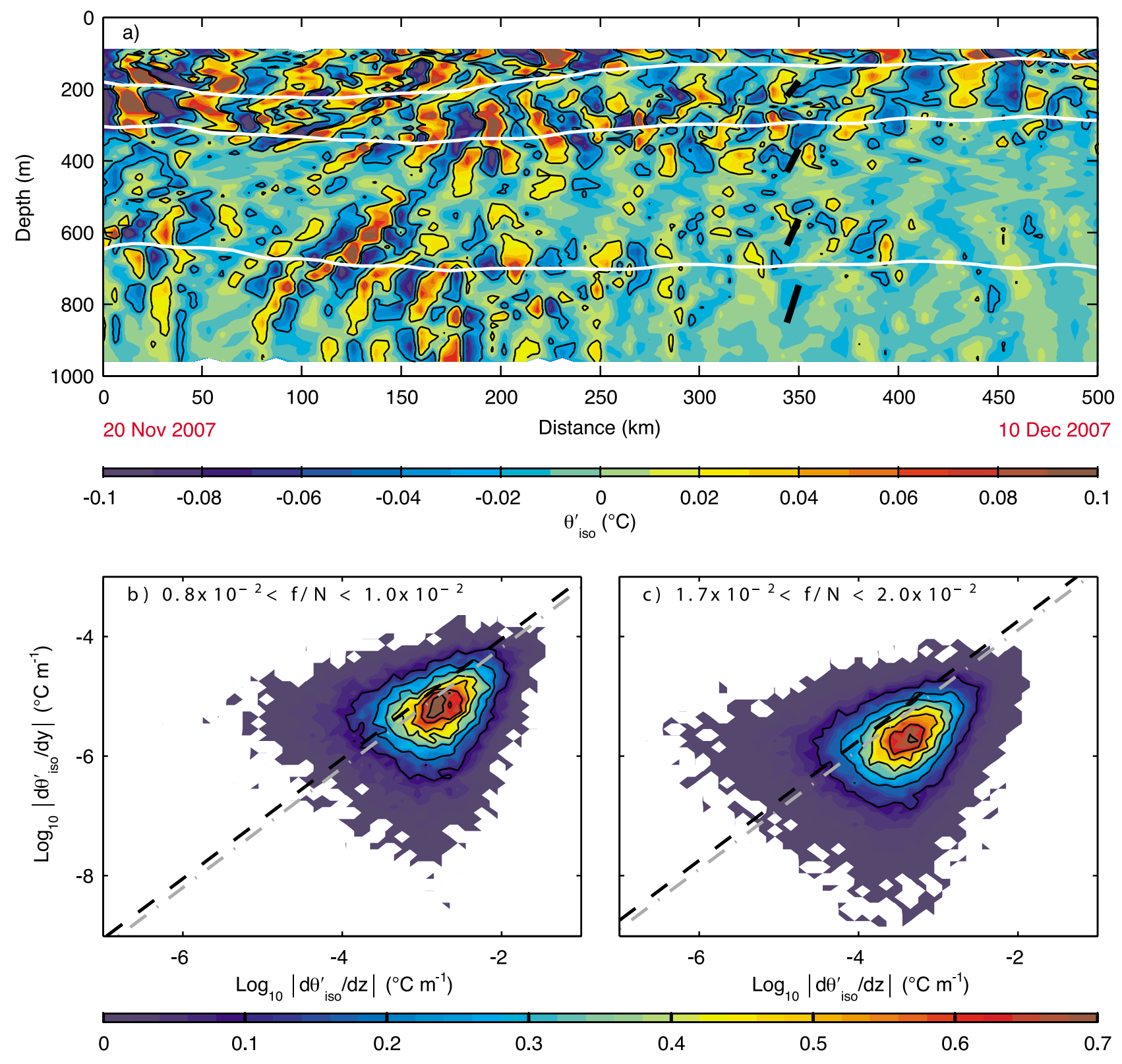

\begin{tabular}{lllllllll}
\hline 0 & 0.1 & 0.2 & 0.3 & & 0.4 & 0.5 & 0.6 & 0.7
\end{tabular}

Figure 10. Slope of a passive tracer. (a) The first $500 \mathrm{~km}$ of a section of isopycnal temperature fluctuations on depth surfaces. Isopycnal temperature is interpolated to depth surfaces using isopycnal depth mapped with a $30 \mathrm{~km}$ length scale (white lines correspond to mapped depths of the 25.0, 26.0 and $27.0 \mathrm{~kg} \mathrm{~m}^{-3}$ density surfaces). Submesoscale fluctuations are considered by removing this field mapped with a $30 \mathrm{~km}$ length scale. Black lines at $350 \mathrm{~km}$ show $\Delta \mathrm{z} / \Delta \mathrm{x}=f / N$ for a $6 \mathrm{~km}$ horizontal difference at four different depths. (b and c) Joint PDFs of the meridional and vertical gradients of isopycnal temperature fluctuations on depth surfaces over all sections. The joint PDFs are for $0.8 \times 10^{-2}<f / N<1.0 \times 10^{-2}$ (Figure 10b) and $1.7 \times 10^{-2}<f / N<2.0 \times 10^{-2}$ (Figure 10c). Lines show the local ratio of $f / N$ (black dashed) and $f / \sqrt{2} N$ (gray dash-dotted).

spectral slopes of -1 [Charney, 1971; Kraichnan, 1974], except near the surface where frontogenesis can result in different slopes, including -2 [Klein et al., 1998]. Previous observations have been limited to the upper $400 \mathrm{~m}$, and show spectral slopes of -2 consistent with a series of fronts [Bernstein and White, 1974; Strass, 1992; Hodges and Rudnick, 2006; Cole et al., 2010]. To calculate isopycnal salinity spectra, each section of $\mathrm{S}_{\text {iso }}$ south of $29^{\circ} \mathrm{N}$ was linearly interpolated to a $0.5 \mathrm{~km}$ uniform grid, a trend was removed, the resulting Fourier coefficients were averaged in adjacent wave number bands with more degrees of freedom at higher wave numbers, and truncated at a $15 \mathrm{~km}$ wavelength. Spectra were averaged over all sections and vertically in density bins (Figure 9a). At all depths in the thermocline, the spectral slope was indistinguishable from -2 . Either the observations do not extend to small enough scale to observe a 

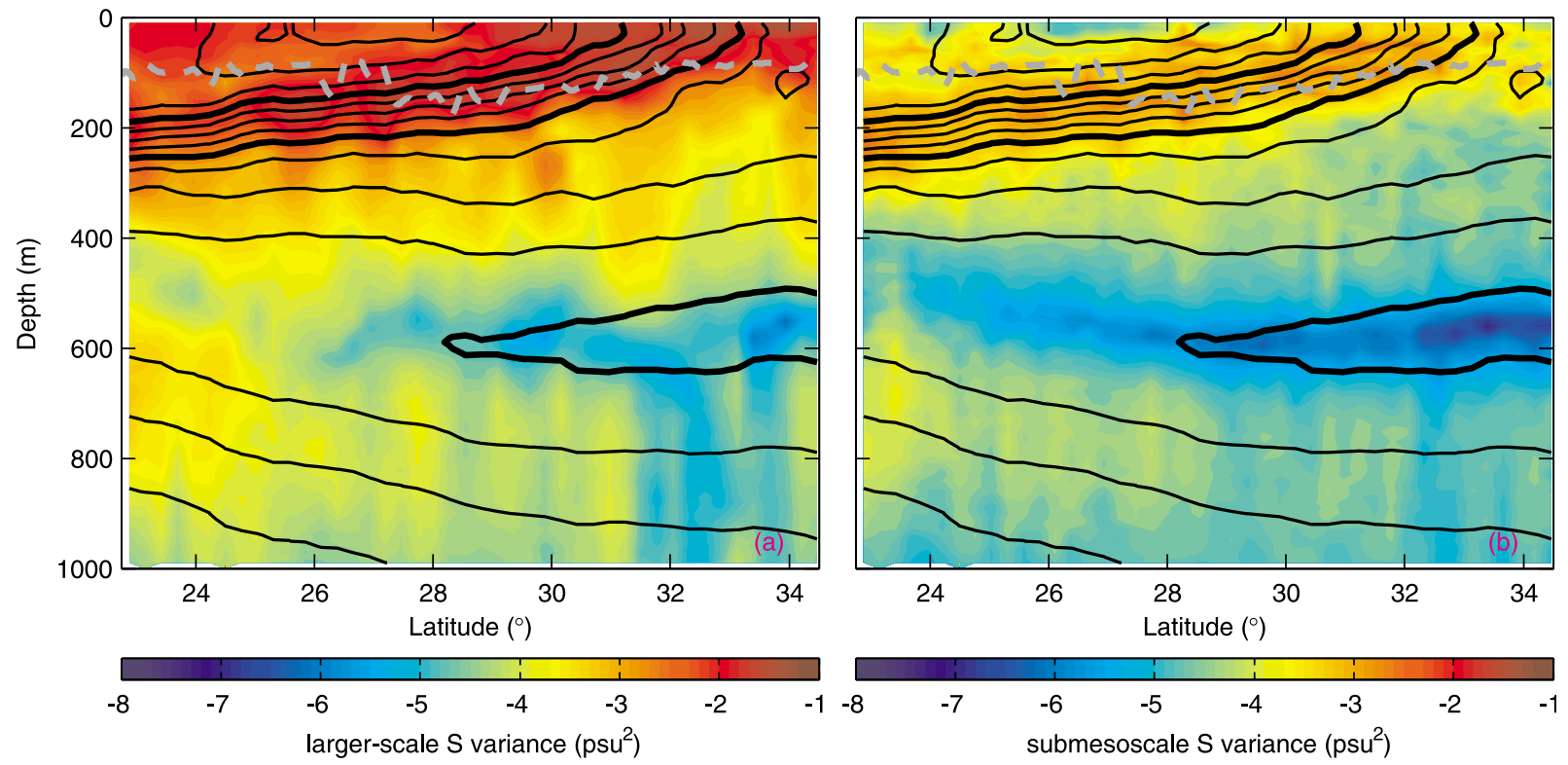

Figure 11. Salinity variance on depth surfaces. (a) Variance at scales greater than $30 \mathrm{~km}$ and one day calculated by using as $\tilde{S}$ in Figure 4a. (b) Submesoscale variance at scales less than $30 \mathrm{~km}$ and one day calculated by using $S^{\prime}$ as in Figure $4 \mathrm{~b}$. Mean salinity contours (black) and the deepest mixed layer base (dashed gray) are shown.

slope other than -2 at depth (the transition to a -1 slope is expected to occur at progressively larger scales with depth), or we do not yet have a complete theoretical understanding of the energy cascade away from the surface.

\subsection{Sloping Submesoscale Features}

[28] We test with observations the numerical modeling result that the slope of a passive tracer stirred in a quasigeostrophic velocity field is $f / N$, with $f$ the Coriolis parameter and $N$ the buoyancy frequency [Smith and Ferrari, 2009]. Glider observations are capable of resolving such steep tracer slopes, which correspond to features 30-120 m tall tilted over a $6 \mathrm{~km}$ distance for our observed $f / N$. On depth surfaces, spice features are masked by isopycnal tilting caused largely by internal waves. To remove internal wave effects, isopycnal temperature is interpolated to depth surfaces mapped with a $30 \mathrm{~km}$ length scale. Then, fluctuations from this field at scales less than $30 \mathrm{~km}$ are considered. Isopycnal temperature fluctuations on depth surfaces were dominated by sloped features (Figure 10a for example), with slopes much steeper than density surfaces and similar to $f / N$ at all depths.

[29] Observed slopes are analyzed using joint probability density functions (PDFs) of the vertical and meridional gradient of $\theta^{\prime}{ }_{\text {iso }}$ on depth surfaces. PDFs were calculated for $0.8 \times 10^{-2}<f / N<1.0 \times 10^{-2}$, typically shallower than $300 \mathrm{~m}$ (Figure 10b), and $1.7 \times 10^{-2}<f / N<2.0 \times 10^{-2}$, typically deeper than $600 \mathrm{~m}$ (Figure 10c). Peak values of the PDFs were near lines corresponding to a slope of $f / N$, with some slopes deviating from this ratio by more than an order of magnitude, consistent with Smith and Ferrari [2009] (compare our Figures 10b and 10c and their Figure 14b). The median observed slope, $\frac{\mid \partial \theta^{\prime} \text { iso } / \partial y \mid}{\partial \theta^{\prime}{ }_{i s o} / \partial z \mid}$, was smaller than $f / N$ by a factor of 2.2 in the upper ocean (Figure 10b), and a factor of 3.5 at deeper depths (Figure 10c). A two-dimensional section does not precisely slice through submesoscale features, so using only the meridional gradient underestimates the true slope. If submesoscale features have no preferred $x-y$ orientation, the root-mean square meridional and zonal gradients will be equal, and the slope will be underestimated by $\sqrt{2}$ (a factor of 1.4). So slopes were essentially in agreement with $f / N$ in the upper ocean, and close to agreement at depth.

\section{Spatial Distribution of Thermohaline Structure on Depth Surfaces}

[30] The spatial distribution of salinity fluctuations on depth surfaces is dominated by processes that tilt isopycnals. To show the submesoscale and larger-scale spatial distribution, the same calculations as in Figure 4 are performed with sections of salinity on depth surfaces (Figure $2 \mathrm{a}$ and $2 \mathrm{~b}$ for example). At all scales, salinity variance spanned three orders of magnitude, was strong in the layer of tightly packed salinity surfaces above $300 \mathrm{~m}$ depth, and weak in the almost vertically uniform salinity minimum region of NPIW (Figure 11). This distribution mirrors the vertical salinity gradient because tilting isopycnals project vertical salinity gradients into horizontal salinity fluctuations [Dzieciuch et al., 2004]. Compensated salinity fluctuations along isopycnals, which also contribute to salinity variance on depth surfaces, were typically smaller than fluctuations from tilting isopycnals. Variance on depth surfaces had similar spatial structure at all observed scales because it resulted from internal waves and geostrophically balanced motions such as eddies and the subtropical fronts tilting the same vertical gradient.

\section{Annual Cycle of Thermohaline Structure}

\subsection{Mixed Layer}

[31] Objective maps of mixed layer properties show a significant annual cycle with smaller interannual differences 

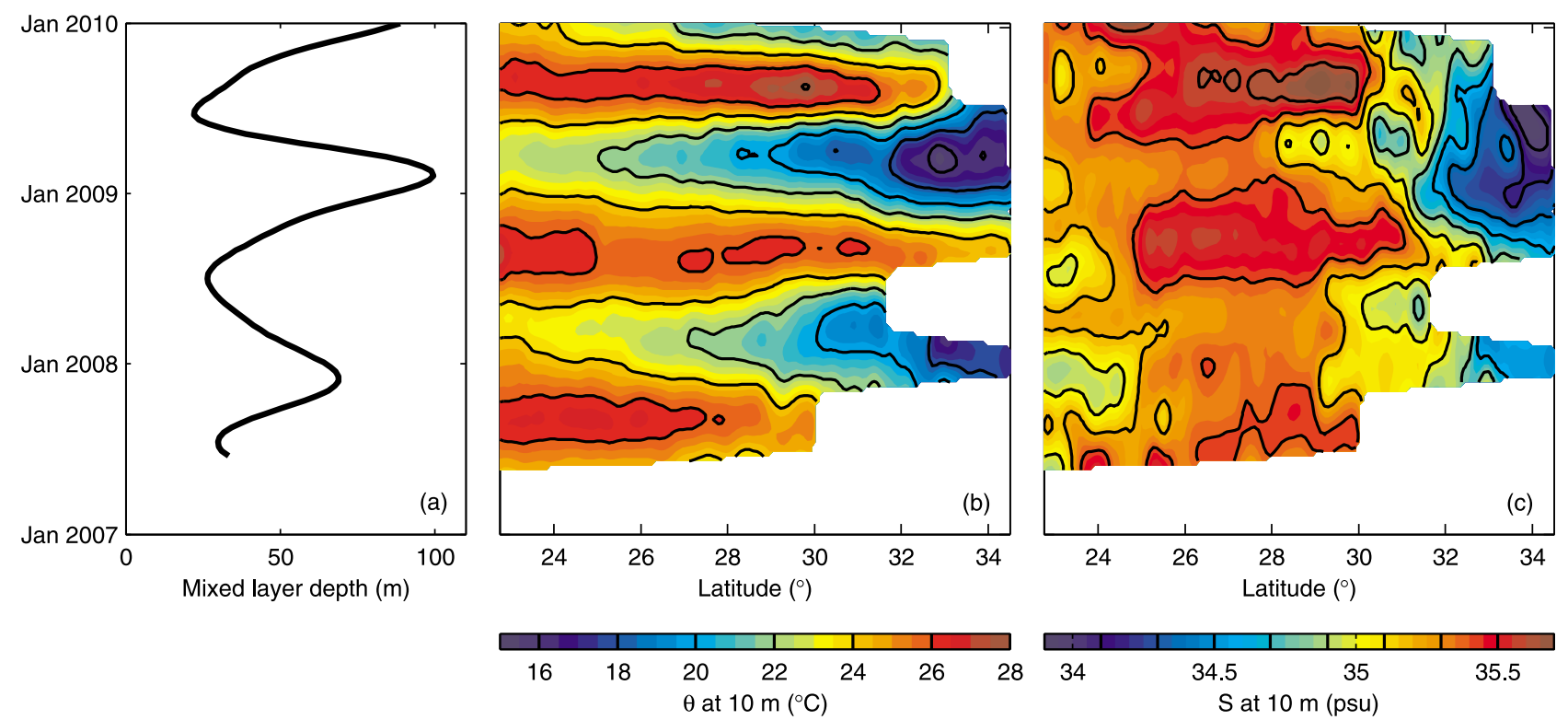

Figure 12. Mixed layer temporal variability. (a) Mixed layer depth objectively mapped with a $30 \mathrm{~km}$ length scale and 120 day time scale and then averaged over $22.75-29^{\circ} \mathrm{N}$. (b) Temperature and (c) salinity at $10 \mathrm{~m}$ depth objectively mapped with a $30 \mathrm{~km}$ length scale and 120 day time scale.

(Figure 12). A $30 \mathrm{~km}$ length scale and 120 day time scale were chosen to focus on seasonal and interannual timescales. Mixed layer temperature and salinity were lowest in December-March, coincident with the deepest mixed layers, and highest in August, about three months after the shallowest mixed layers occurred. Annual changes in temperature and salinity, $4-9^{\circ} \mathrm{C}$ and $0.4-1.0 \mathrm{psu}$, were largest near the $32^{\circ} \mathrm{N}$ frontal region. Both frontal regions had annual cycles in the latitude, width, and magnitude of their horizontal gradients, consistent with previous studies [White et al., 1978; Kazmin and Rienecker, 1996; Dinniman and Rienecker, 1999]. Interannual differences were evident, such as 2009 having deeper mixed layers and colder temperatures in winter, a saltier salinity maximum region in summer, and saltier water south of the $25^{\circ} \mathrm{N}$ frontal region.

\subsection{Remnant Mixed Layer and Upper Permanent Thermocline}

[32] A composite year of temperature and stratification shows how the annual cycle decays with depth and density (Figure 13). $\theta$ and $\mathrm{N}^{2}$ on both depth and density surfaces were objectively mapped with a $30 \mathrm{~km}$ length scale and 120 day time scale onto a single year, and then averaged over $22.75-29^{\circ} \mathrm{N}$, which is south of the $32^{\circ} \mathrm{N}$ frontal region. An annual cycle was observed shallower than approximately $200 \mathrm{~m}$ and $25.1 \mathrm{~kg} \mathrm{~m}^{-3}$, which was slightly deeper than the deepest instantaneously observed mixed layer base of $160 \mathrm{~m}$ and $24.9 \mathrm{~kg} \mathrm{~m}^{-3}$. Temperature was warmest in August and coldest in March as in the mixed layer (Figure 13a and 13c). Temperature along isopycnals was nearly constant and so temperature changed primarily as isopycnals restratified from or were entrained into the mixed layer (Figure 13c). Stratification was weak in the mixed layer, with restratification in spring leaving behind weak stratification in the remnant mixed layer and stronger stratification below in the winter transition layer (the local maximum near $150 \mathrm{~m}$ depth and $24.8 \mathrm{~kg} \mathrm{~m}^{-3}$ [Johnston and Rudnick, 2009]). These spring extrema in stratification weakened with time because of diapycnal mixing with surrounding waters. Mixed layer heating through August packed additional isopycnals into the remnant mixed layer, which also weakened the spring stratification minimum.

[33] Spice fluctuations also have an annual cycle, which reflects how surface forcing, advection, and diffusion modify thermohaline structure. A composite year of isopycnal salinity variance was constructed by calculating the variance of $S^{\prime}{ }_{\text {iso }}$ over $22.75-29^{\circ} \mathrm{N}$ for each section and then objectively mapping onto a single year with a 120 day time scale (Figure 14). Shallower than $24.5 \mathrm{~kg} \mathrm{~m}^{-3}$, variance left behind during restratification in spring increased with time because these isopycnals were influenced by the $25^{\circ} \mathrm{N}$ front that had a stronger gradient in summer (Figure 12c). Near $24.7 \mathrm{~kg} \mathrm{~m}^{-3}$, the elevated variance in April decayed with time reaching a minimum in January, consistent with large thermohaline fluctuations inherited from the mixed layer during restratification that weaken because of a net diffusion. A modest annual cycle was observed in the low variance layer near $25.3 \mathrm{~kg} \mathrm{~m}^{-3}$ and the high variance layer near $25.8 \mathrm{~kg} \mathrm{~m}^{-3}$, possibly because of seasonal variability near the subduction region advected to our section.

[34] Spectra of $S_{\text {iso }}$ were calculated for the region of highest variance near $24.7 \mathrm{~kg} \mathrm{~m}^{-3}$ to determine what horizontal scales varied seasonally (Figure 9b). Spectra were calculated in the same way as in section 3.2, averaged vertically over $24.6-24.8 \mathrm{~kg} \mathrm{~m}^{-3}$ near the bottom of the remnant mixed layer, and averaged over three sections in Apr-May when variance was largest and three sections in Nov-Dec when variance was smaller (Figure 14). From Apr-May to Nov-Dec, variance decreased at all wavelengths from 15 to $280 \mathrm{~km}$; the decrease was significant at the $90 \%$ confidence level over 15-45 km wavelengths (Figure $9 \mathrm{~b}$ and Table 2). Variance decreased by a factor of 4.7 over $15-28 \mathrm{~km}$ 

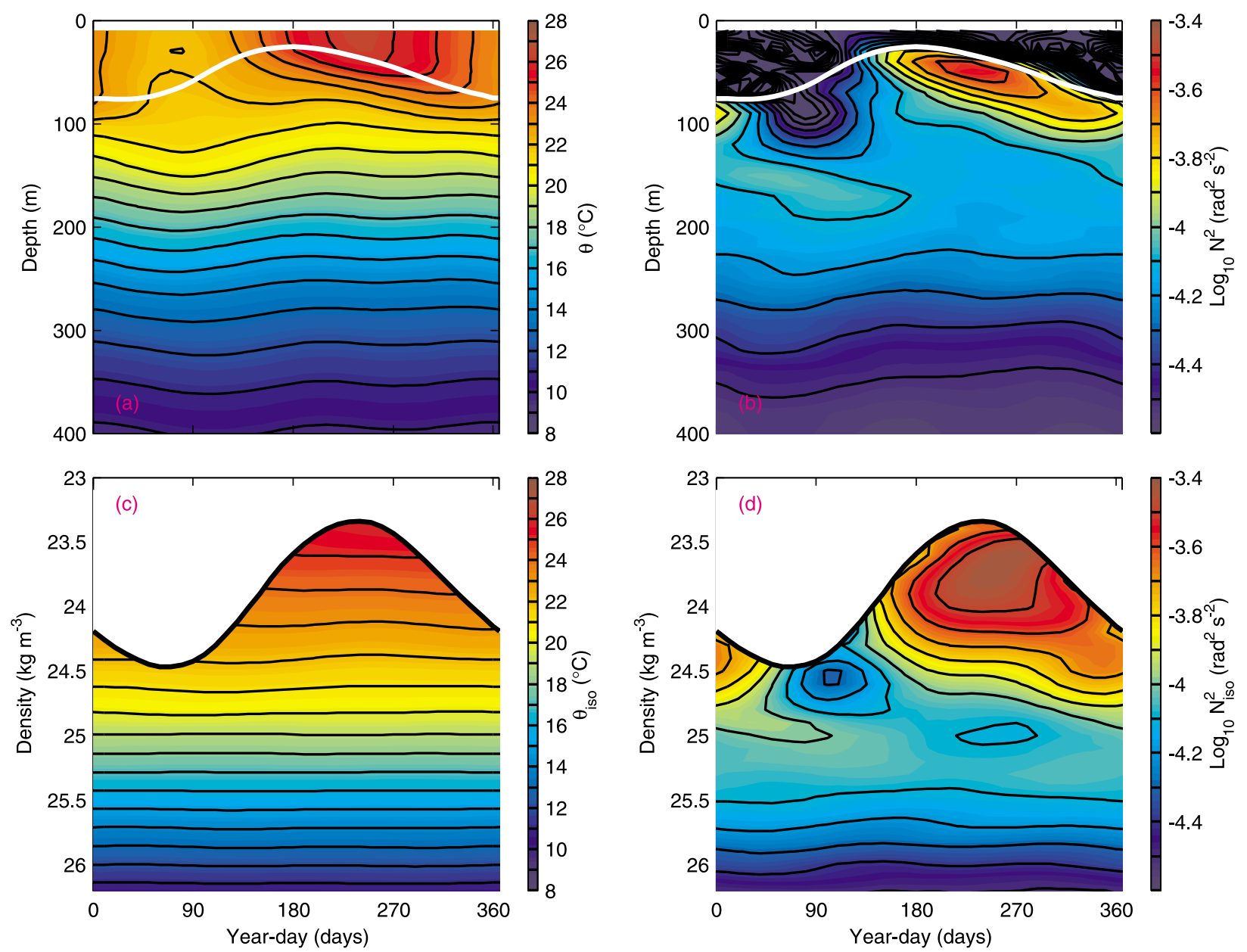

Figure 13. Annual cycle as a function of depth and density. Mean over $22.75-29^{\circ} \mathrm{N}$ of $(\mathrm{a}, \mathrm{c})$ temperature and $(b, d)$ stratification on depth surfaces (Figures 13a and 13b) and density surfaces (Figures 13c and 13d) after objective mapping onto a single year with a $30 \mathrm{~km}$ length scale and 120 day time scale. Similarly mapped mixed layer depth (white; Figures 13a and 13b) and mixed layer density (black; Figures 13c and $13 \mathrm{~d})$ are shown.

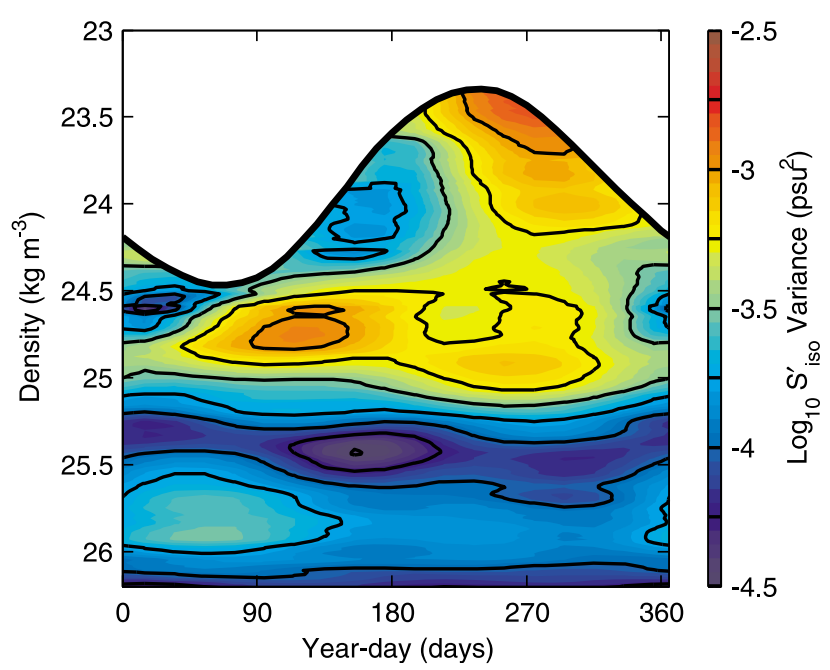

Figure 14. Annual cycle of $S_{\text {iso }}$ fluctuations. Variance of $S_{i s o}^{\prime}$ is calculated over $22.75-29^{\circ} \mathrm{N}$ for each section, and then objectively mapped onto a single year with a 120 day time scale. Mixed layer density (black) as in Figure 13. wavelengths and by a factor of 3.4 over $35-45 \mathrm{~km}$ wavelengths (Table 2).

[35] Diffusivity at resolved scales was estimated from the observed decrease in spice variance. Assuming simple diffusion of $S_{i s o}, \frac{\partial S_{i s o}}{\partial t}=\kappa_{h} \frac{\partial^{2} S_{i s o}}{\partial x^{2}}$, spectra of $\mathrm{S}_{\text {iso }}$ obey

$$
S_{\text {iso }}(k, t+\Delta t)=S_{\text {iso }}(k, t) \exp \left[-2 k \kappa_{h} \Delta t\right],
$$

where $k$ is wavelength [Cole et al., 2010]. $\kappa_{\mathrm{h}}$ solved for in a least squares sense for the Apr-May to Nov-Dec decrease

Table 2. Statistics of $S_{\text {iso }}$ Spectra Over $22.75-29^{\circ} \mathrm{N}$ in the Remnant Mixed Layer for Time Periods Corresponding to Dates Listed in Figure 9b

\begin{tabular}{|c|c|c|c|c|c|}
\hline \multirow{2}{*}{$\begin{array}{l}\text { Wavelengths } \\
\qquad(\mathrm{km})\end{array}$} & \multicolumn{2}{|c|}{$\begin{array}{c}\text { Variance } \\
\left(\mathrm{psu}^{2} \times 10^{4}\right)\end{array}$} & \multicolumn{2}{|c|}{$\begin{array}{c}90 \% \text { Variance } \\
\text { Confidence Interval } \\
\left(\mathrm{psu}^{2} \times 10^{4}\right)\end{array}$} & \multirow{2}{*}{$\underset{\left(\mathrm{m}^{2} \mathrm{~s}^{-1}\right)}{\mathrm{K}^{\mathrm{a}}}$} \\
\hline & Apr-May & Nov-Dec & Apr-May & Nov-Dec & \\
\hline $15-23$ & 5.9 & 1.3 & $5.1-6.9$ & $1.1-1.6$ & 0.4 \\
\hline $28-45$ & 13.1 & 3.7 & $10.7-16.6$ & $2.9-4.9$ & 0.9 \\
\hline
\end{tabular}

${ }^{\mathrm{a}}$ Horizontal diffusivity from Apr- May and Nov-Dec. 
near $24.7 \mathrm{~kg} \mathrm{~m}^{-3}$ (Figures $9 \mathrm{~b}$ and 14) was $0.4 \mathrm{~m}^{2} \mathrm{~s}^{-1}$ over 15-28 km wavelengths and $0.9 \mathrm{~m}^{2} \mathrm{~s}^{-1}$ over $35-45 \mathrm{~km}$ wavelengths (Table 2). A previous estimate of $\kappa_{\mathrm{h}}$ in the remnant mixed layer using this method was slightly larger at $1.4 \mathrm{~m}^{2} \mathrm{~s}^{-1}$ over $30-46 \mathrm{~km}$ wavelengths [Cole et al., 2010]. Previous estimates from tracer release experiments were similar at $0.3-6 \mathrm{~m}^{2} \mathrm{~s}^{-1}$ over 1-30 km scales [Ledwell et al., 1998; Sundermeyer and Ledwell, 2001]. Unlike injected tracers, thermohaline fluctuations had sources and sinks throughout the time period considered. The estimated diffusivity is a minimum value representing variance lost to smaller scales through diffusion as well as variance gained from stirring at larger scales. An uncertainty is caused by the spatial variability observed in spice fluctuations (Figure 4) as the spring and fall water observed at $158^{\circ} \mathrm{W}$ may have originated at different locations. However, the general agreement between our diffusivity estimates and those from tracer release experiments is encouraging.

\section{Summary and Conclusions}

[36] This study addressed the relationship between thermohaline structure and the dominant processes in the upper ocean. Sustained observations over 2.5 years and 5-1300 km scales allowed temporal and spatial variability to be investigated. On density surfaces, thermohaline structure serves as a tracer provided by nature. Thermohaline structure was set at the surface, left behind along isopycnals during restratification, and then advected throughout the ocean forming persistent layers of spice variance. These observations are among the first to show persistent layering in thermohaline fluctuations. This study shows how spice is influenced by the initial surface fluctuations and the history of advection, diffusion, and diapycnal mixing (see (1)).

[37] Thermohaline structure in the subtropical North Pacific was set largely by stirring. Below $400 \mathrm{~m}$ depth, thermohaline fluctuations were elevated where both stirring velocities and the gradient available to stir were enhanced. It was not possible to determine whether the increased stirring velocities or the enhanced large-scale gradient was more important in elevating thermohaline fluctuations. In the upper $400 \mathrm{~m}$, stirring aligned fluctuations vertically across different layers of spice variance. In the remnant mixed layer, the enhanced large-scale gradient at the subtropical frontal regions elevated submesoscale fluctuations by about an order of magnitude.

[38] In the upper $400 \mathrm{~m}$ south of $30^{\circ} \mathrm{N}$, three layers of salinity variance stirred by the same velocity field resulted from larger variance initially subducted on certain isopycnals. Differences at the subduction region were not explicitly shown, but such differences are consistent with (1) dissolved oxygen and stratification observations that suggest a different history for each layer, (2) the uncorrelated vertical structure of salinity fluctuations, and (3) previous studies of North Pacific circulation. Diapycnal mixing between the two layers with elevated but uncorrelated fluctuations also decreased variance within the layer of low variance.

[39] Water age, or the time over which thermohaline gradients were diffused, was of lesser importance. Larger gradients were usually observed closer to the surface where water was younger, particularly in the remnant mixed layer.
Vertical layering of salinity fluctuations near the surface and horizontal modulations at depth shows that other processes largely determined the magnitude of thermohaline fluctuations.

[40] These observations are consistent with a cascade of variance from large to small scales. Mesoscale and submesoscale fluctuations in the remnant mixed layer and deeper ocean were stronger where large-scale gradients were elevated. All sections had a similar spatial distribution of spice fluctuations, indicating that the implied cascade was persistent in time.

[41] Spice features on depth surfaces had slopes near but somewhat smaller than $f / N$, in agreement with quasi-geostrophic model results [Smith and Ferrari, 2009]. Slopes in the upper ocean were closer to the local value of $f / N$ than those at deeper depths. An open question is whether relevant dynamical ratios, such as that of strain to shear, also scale as f/N in observations. While our measurements of spice cannot answer that question, the implication that velocity features may have a similar scaling is worth further investigation.

[42] On depth surfaces, salinity fluctuations resulted primarily from tilting isopycnals that projected vertical salinity gradients into horizontal fluctuations. So the spatial distribution of salinity variance mirrored the vertical salinity gradient, which implies a uniform geography for the internal wavefield and mesoscale and submesoscale features that tilted isopycnals.

[43] With 2.5 years of observations, the annual cycle of thermohaline fluctuations was investigated. Gliders are advantageous compared with satellites [e.g., Kazmin and Rienecker, 1996], floats [e.g., Wong and Johnson, 2003; Ohno et al., 2009], long-term stations such as ALOHA [e.g., Bingham and Lukas, 1996], and climatologies [e.g., Kara et al., 2000] because they can sample the same section repeatedly and provide a large number of profiles over a short time period. Mesoscale and larger-scale thermohaline structure, including the subtropical fronts, primarily had an annual cycle with smaller interannual differences. In the remnant mixed layer, mean temperature and stratification changed seasonally primarily because of density changes as isopycnals restratified from and were entrained into the mixed layer. Large spice fluctuations left behind during restratification near the base of the remnant mixed layer weakened from spring to fall because of a net diffusion. Estimated diffusivities were $0.4 \mathrm{~m}^{2} \mathrm{~s}^{-1}$ over $15-28 \mathrm{~km}$ wavelengths and $0.9 \mathrm{~m}^{2} \mathrm{~s}^{-1}$ over $35-45 \mathrm{~km}$ wavelengths, in agreement with previous estimates (see section 5.2). This diffusivity most likely resulted from eddy activity, although other sources are possible such as dispersion from nonlinear internal waves [Sanderson and Okubo, 1988; HolmesCerfon et al., 2011]. Deeper in the thermocline, thermohaline structure varied in time, but did not have a large annual cycle.

[44] Further progress in understanding thermohaline structure can be made using existing observations. Our observations were just long enough in time to investigate the annual cycle and the persistence of the spatial distribution. A wider range of timescales or the vertical structure of spice fluctuations could be investigated from time series such as moorings. Globally, spice variance could be estimated at a 500-1000 km scale from Argo. Such analyses would reveal the spatial distribution of thermohaline structure over most 
of the ocean, and determine the origin, formation process, and termination of spice variance layers. Hot spots of spice variance that result from increased stirring, large fluctuations initially subducted, or other processes, could be identified. Future observations, whether longer sections, different locations, or targeted at hot spots will extend our understanding of advection, diffusion, and thermohaline structure.

[45] Acknowledgments. We gratefully acknowledge the National Science Foundation for funding this work under grant number OCE0452574. The Instrument Development Group at Scripps Institution of Oceanography and its director Russ Davis built, deployed, operated, and recovered the Spray gliders used in this study. We also acknowledge those involved with collecting and publicizing the oxygen observations at station ALOHA and along $152^{\circ} \mathrm{W}$.

\section{References}

Antonov, J. I., R. A. Locarnini, T. P. Boyer, A. V. Mishonov, and H. E Garcia (2006), World Ocean Atlas 2005, vol. 2, Salinity, NOAA Atlas NESDIS, vol. 62, edited by S. Levitus, 182 pp., NOAA, Silver Spring, $\mathrm{Md}$

Bernstein, R. L., and W. B. White (1974), Time and length scales of baroclinic eddies in the central North Pacific Ocean, J. Phys. Oceanogr., 4 613-624, doi:10.1175/1520-0485(1974)004<0613:TALSOB >2.0.CO;2.

Bingham, F. M., and R. Lukas (1996), Seasonal cycles of temperature, salinity, and dissolved oxygen observed in the Hawaii Ocean Time-Series, Deep Sea Res., Part II, 43, 199-213, doi:10.1016/0967-0645(95)00090-9.

Bingham, F. M., T. Suga, and K. Hanawa (2002), Origin of waters observed along $137^{\circ} \mathrm{E}, \mathrm{J}$. Geophys. Res., 107(C7), 3073, doi:10.1029/2000JC000722.

Bingham, F. M., G. R. Foltz, and M. J. McPhaden (2010), Seasonal cycles of surface layer salinity in the Pacific Ocean, Ocean Sci., 6, 775-787, doi:10.5194/os-6-775-2010.

Bostock, H. C., B. N. Opdyke, and M. J. M. Williams (2010), Characterizing the intermediate depth waters of the Pacific Ocean using $\delta^{13} \mathrm{C}$ and other geochemical tracers, Deep Sea Res., Part I, 57, 847-859, doi:10.1016/j. dsr.2010.04.005

Bullister, J. L., D. P. Wisegarver, and R. E. Sonnerup (2006), Sulfer hexafluoride as a transient tracer in the North Pacific Ocean, Geophys. Res. Lett., 33, L18603, doi:10.1029/2006GL026514.

Capet, X., J. C. McWilliams, M. J. Molemaker, and A. F. Shchepetkin (2008), Mesoscale to submesoscale transition in the California Current System. Part 1: Flow structure, eddy flux and observational tests, J. Phys. Oceanogr., 38, 29-43, doi:10.1175/2007JPO3671.1.

Castelao, R., S. Glenn, and O. Schofield (2010), Temperature, salinity, and density variability in the central Middle Atlantic Bight, J. Geophys. Res., 115, C10005, doi:10.1029/2009JC006082.

Charney, J. G. (1971), Geostrophic turbulence, J. Atmos. Sci., 28, 1087-1095, doi:10.1175/1520-0469(1971)028<1087:GT>2.0.CO;2.

Chelton, D. B., R. A. DeSzoeke, M. G. Schlax, K. E. Naggar, and N. Siwertz (1998), Geographical variability of the first baroclinic Rossby radius of deformation, J. Phys. Oceanogr., 28, 433-460, doi:10.1175/1520-0485(1998) 028<0433:GVOTFB $>2.0 . \mathrm{CO} ; 2$.

Chen, S., and B. Qiu (2010), Mesoscale eddies northeast of the Hawaiian archipelago from satellite altimeter observations, J. Geophys. Res., 115 C03016, doi:10.1029/2009JC005698.

Cole, S. T., D. L. Rudnick, and J. A. Colosi (2010), Seasonal evolution of upper ocean horizontal structure and the remnant mixed layer, J. Geophys. Res., 115, C04012, doi:10.1029/2009JC005654.

Davis, R. E., M. D. Ohman, D. L. Rudnick, J. T. Sherman, and B. Hodges (2008), Glider surveillance of physics and biology in the southern California Current System, Limnol. Oceanogr., 53, 2151-2168, doi:10.4319/ lo.2008.53.5 part_2.2151.

Dinniman, M. S., and M. M. Rienecker (1999), Frontogenesis in the North Pacific oceanic frontal zones-A numerical simulation, J. Phys. Oceanogr. 29, 537-559, doi:10.1175/1520-0485(1999)029<0537:FITNPO >2.0.CO;2.

Dzieciuch, M., W. Munk, and D. L. Rudnick (2004), Propagation of sound through a spicy ocean, the SOFAR overture, J. Acoust. Soc. Am., 116, 1447-1462, doi:10.1121/1.1772397.

Ferrari, R., and F. Paparella (2003), Compensation and alignment of thermohaline gradients in the ocean mixed layer, J. Phys. Oceanogr., 33, 2214-2223, doi:10.1175/1520-0485(2003)033<2214:CAAOTG $>2.0$. CO;2.

Ferrari, R., and K. L. Polzin (2005), Finescale structure of the T-S relation in the Eastern North Atlantic, J. Phys. Oceanogr., 35, 1437-1454, doi:10.1175/JPO2763.1.

Ferrari, R., and D. L. Rudnick (2000), Thermohaline variability in the upper ocean, J. Geophys. Res., 105, 16,857-16,883, doi:10.1029/2000JC900057.
Fine, R. A., K. A. Maillet, K. F. Sullivan, and D. Willey (2001), Circulation and ventilation flux of the Pacific Ocean, J. Geophys. Res., 106, 22,159-22,178, doi:10.1029/1999JC000184

Fox-Kemper, B., G. Danabasoglu, R. Ferrari, S. M. Griffies, R. W. Hallberg, M. M. Holland, M. E. Maltrud, S. Peacock, and B. L. Samuels (2011) Parameterization of mixed layer eddies. Part III: Implementation and impact in global ocean climate simulations, Ocean Modell., 39, 61-78, doi:10.1016/j.ocemod.2010.09.002.

Gregg, M. C. (1980), The three-dimensional mapping of a small thermohaline intrusion, J. Phys. Oceanogr., 10, 1468-1492, doi:10.1175/15200485(1980)010<1468:TTDMOA>2.0.CO;2.

Hall, M. M., P. P. Niiler, and W. J. Schmitz (1997), Circulation in the eastern North Pacific: Results from a current meter array along $152^{\circ} \mathrm{W}$, Deep Sea Res., Part I, 44, 1127-1146, doi:10.1016/S0967-0637(97)00015-0.

Hautala, S. R., and D. H. Roemmich (1998), Subtropical mode water in the northeast Pacific Basin, J. Geophys. Res., 103, 13,055-13,066, doi:10.1029/ 98JC01015.

Hodges, B. A., and D. L. Rudnick (2006), Horizontal variability in chlorophyll fluorescence and potential temperature, Deep Sea Res., Part I, 53, 1460-1482, doi:10.1016/j.dsr.2006.06.006.

Holmes-Cerfon, M., O. Bühler, and R. Ferrari (2011), Partical dispersion by random waves in the rotating Boussinesq system, J. Fluid Mech. 670, 150-175, doi:10.1017/S0022112010005240.

James, C., M. Tomczak, I. Helmond, and L. Pender (2002), Summer and winter surveys of the Subtropical Front of the southeastern Indian Ocean 1997-1998, J. Mar. Syst., 37, 129-149, doi:10.1016/S0924-7963(02)00199-9.

Johnston, T. M. S., and D. L. Rudnick (2009), Observations of the transition layer, J. Phys. Oceanogr., 39, 780-797, doi:10.1175/2008JPO3824.1.

Joyce, T. M., J. R. Luyten, A. Kubryakov, F. B. Bahr, and J. S. Pallant (1998), Meso- to large-scale structure of subducting water in the subtropical gyre of the eastern North Atlantic Ocean, J. Phys. Oceanogr., 28, 40-61, doi:10.1175/1520-0485(1998)028<0040:MTLSSO >2.0.CO;2.

Kara, A. B., P. A. Rochford, and H. E. Hulbert (2000), Mixed layer depth variability and barrier layer formation of the North Pacific Ocean, J. Geophys. Res, 105, 16,783-16,801, doi:10.1029/2000JC900071.

Karl, D. M., and R. Lukas (1996), The Hawaii Ocean Time-Series (HOT) program: Background, rationale, and field implementation, Deep Sea Res., Part II, 43, 129-156, doi:10.1016/0967-0645(96)00005-7.

Kazmin, A. S., and M. M. Rienecker (1996), Variability and frontogenesis in the large-scale oceanic frontal zones, J. Geophys. Res., 101, 907-921, doi:10.1029/95JC02992.

Klein, P., A.-M. Treguier, and B. L. Hua (1998), Three-dimensional stirring of thermohaline fronts, J. Mar. Res., 56, 589-612, doi:10.1357/ 002224098765213595 .

Kraichnan, R. H. (1974), Convection of a passive scalar by a quasi-uniform random scaling field, J. Fluid Mech., 64, 737-762, doi:10.1017/ S0022112074001881.

Ladd, C., C. W. Mordy, N. B. Kachel, and P. J. Stabeno (2007), Northern Gulf of Alaska eddies and associated anomalies, Deep Sea Res., Part I, 54, 487-509, doi:10.1016/j.dsr.2007.01.006.

Ledwell, J. R., A. J. Watson, and C. S. Law (1998), Mixing of a tracer in the pycnocline, J. Geophys. Res., 103, 21,499-21,529, doi:10.1029/98JC01738.

Lévy, M., P. Klein, A.-M. Tréguier, D. Iovino, G. Madec, S. Masson, and K. Takahashi (2010), Modifications of gyre circulation by sub-mesoscale physics, Ocean Modell., 34, 1-15, doi:10.1016/j.ocemod.2010.04.001.

Lilly, J. M., P. B. Rhines, M. Visbeck, R. Davis, J. R. N. Lazier, F. Schott, and D. Farmer (1999), Observing deep convection in the Labrador Sea during winter 1994/1995, J. Phys. Oceanogr., 29, 2065-2098, doi:10.1175/1520-0485(1999)029<2065:ODCITL > 2.0.CO;2.

Locarnini, R. A., A. V. Mishonov, J. I. Antonov, T. P. Boyer, and H. E. Garcia (2006), World Ocean Atlas 2005, vol. 1, Temperature, NOAA Atlas NESDIS, vol. 61, edited by S. Levitus, 182 pp., NOAA, Silver Spring, Md.

Macdonald, A. M., S. Mecking, P. E. Robbins, J. M. Toole, G. C. Johnson, L. Talley, M. Cook, and S. E. Wijffels (2009), The WOCE-era 3-D Pacific ocean circulation and heat budget, Prog. Oceanogr., 82, 281-325, doi:10.1016/j.pocean.2009.08.002.

McDougall, T. J. (1987), Neutral surfaces, J. Phys. Oceanogr., 17, 1950-1964, doi:10.1175/1520-0485(1987)017<1950:NS>2.0.CO;2.

Moisan, J. R., and P. P. Niiler (1998), The seasonal heat budget of the North Pacific: Net heat flux and heat storage rates (1950-1990), J. Phys. Oceanogr. 28, 401-421, doi:10.1175/1520-0485(1998)028<0401:TSHBOT >2.0.CO;2.

Munk, W. (1981), Internal waves and small-scale processes, in Evolution of Physical Oceanography: Scientific Surveys in Honor of Henry Stommel, edited by B. A. Warren and C. Wunsch, pp. 264-291, MIT Press, Cambridge, Mass.

Ohno, Y., N. Iwasaka, F. Kobashi, and Y. Sato (2009), Mixed layer depth climatology of the North Pacific based on Argo observations, J. Oceanogr., 65, 1-16, doi:10.1007/s10872-009-0001-4. 
Oka, E., S. Kouketsu, K. Toyama, K. Uehara, T. Kobayashi, S. Hosoda, and T. Suga (2011), Formation and subduction of Central Mode Water based on profiling float data 2003-2008, J. Phys. Oceanogr., 41, 113-129, doi:10.1175/2010JPO4419.1.

Perry, M. J., B. S. Sackmann, C. C. Eriksen, and C. M. Lee (2008), Seaglider observations of blooms and subsurface chlorophyll maxima off the Washington coast, Limnol. Oceanogr., 53, 2169-2179, doi:10.4319/ lo.2008.53.5 part 2.2169.

Reid, J. L. (1973), The shallow salinity minima of the Pacific Ocean, Deep Sea Res. Oceanogr. Abstr., 20, 51-68.

Reid, J. L. (1997), On the total geostrophic circulation of the Pacific Ocean: Flow patterns, tracers, and transports, Prog. Oceanogr., 39, 263-352, doi:10.1016/S0079-6611(97)00012-8.

Roden, G. I. (1974), Thermohaline structure, fronts, and sea-air energy exchange of the trade wind region east of Hawaii, J. Phys. Oceanogr., 4 , 168-182, doi:10.1175/1520-0485(1974)004<0168:TSFASA>2.0.CO;2.

Roden, G. I. (1991), Mesoscale flow and thermohaline structure around Fieberling Seamount, J. Geophys. Res., 96, 16,653-16,672, doi:10.1029/ 91JC01747.

Rudnick, D. L., and S. T. Cole (2011), On sampling the ocean using underwater gliders, J. Geophys. Res., 116, C08010, doi:10.1029/2010JC006849.

Rudnick, D. L., and R. Ferrari (1999), Compensation of horizontal temperature and salinity gradients in the ocean mixed layer, Science, 283, 526-529, doi:10.1126/science.283.5401.526

Rudnick, D. L., R. E. Davis, C. C. Eriksen, D. M. Fratantoni, and M. J. Perry (2004), Underwater gliders for ocean research, Mar. Technol. Soc. J., 38, 73-84, doi:10.4031/002533204787522703.

Sanderson, B. G., and A. Okubo (1988), Diffusion by internal waves, J. Geophys. Res., 93, 3570-3582, doi:10.1029/JC093iC04p03570.

Scharffenberg, M. G., and D. Stammer (2010), Seasonal variations of the large-scale geostrophic flow field and eddy kinetic energy inferred from the TOPEX/Poseidon and Jason-1 tandem mission data, J. Geophys. Res., 115, C02008, doi:10.1029/2008JC005242.

Shcherbina, A. Y., M. C. Gregg, M. H. Alford, and R. R. Harcourt (2010), Three-dimensional structure and temporal evolution of submesoscale thermohaline intrusions in the North Pacific Subtropical Frontal Zone, J. Phys. Oceanogr., 40, 1669-1689, doi:10.1175/2010JPO4373.1.

Sherman, J., R. E. Davis, W. B. Owens, and J. Valdes (2001), The autonomous underwater glider "Spray", IEEE J. Oceanic Eng., 26, 437-446, doi:10.1109/48.972076.

Smith, K. S., and R. Ferrari (2009), The production and dissipation of compensated thermohaline variance by mesoscale stirring, J. Phys. Oceanogr. 39, 2477-2501, doi:10.1175/2009JPO4103.1.

Stammer, D., and C. Wunsch (1999), Temporal changes in eddy energy of the oceans, Deep Sea Res., Part II, 46, 77-108, doi:10.1016/S0967-0645(98) 00106-4.

Stammer, D., S. Park, A. Kohl, R. Lukas, and F. Santiago-Mandujano (2008), Causes for large-scale hydrographic changes at the Hawaiian Ocean Time Series station, J. Phys. Oceanogr., 38, 1931-1948, doi:10.1175/ 2008JPO3751.1.
Strass, V. H. (1992), Chlorophyll patchiness caused by mesoscale upwelling at fronts, Deep Sea Res., Part A, 39, 75-96, doi:10.1016/0198-0149(92) 90021-K.

Strass, V. H., H. Leach, and J. D. Woods (1992), On the seasonal development of mesoscale variability: The influence of the seasonal pycnocline formation, Deep Sea Res., Part A, 39, 1627-1639, doi:10.1016/0198 0149(92)90052-U.

Suga, T., K. Motoki, Y. Aoki, and A. Macdonald (2004), The North Pacific climatology of winter mixed layer and mode waters, J. Phys. Oceanogr. 34, 3-22, doi:10.1175/1520-0485(2004)034<0003:TNPCOW >2.0.CO;2.

Sundermeyer, M. A., and J. R. Ledwell (2001), Lateral dispersion over the continental shelf: Analysis of dye release experiments, J. Geophys. Res., 106, 9603-9621, doi:10.1029/2000JC900138.

Talley, L. D. (1993), Distribution and formation of North Pacific intermediate water, J. Phys. Oceanogr., 23, 517-537, doi:10.1175/1520-0485(1993) $023<0517:$ DAFONP $>2.0 . \mathrm{CO} ; 2$

Talley, L. D., and R. A. DeSzoeke (1986), Spatial fluctuations north of the Hawaiian Ridge, J. Phys. Oceanogr., 16, 981-984, doi:10.1175/15200485(1986)016<0981:SFNOTH $>2.0 . \mathrm{CO} ; 2$.

Todd, R. E., D. L. Rudnick, M. R. Mazloff, R. E. Davis, and B. D. Cornuelle (2011), Poleward flows in the southern California Current System: Glider observations and numerical simulation, J. Geophys. Res., 116, C02026, doi:10.1029/2010JC006536.

Veronis, G. (1972), Properties of seawater defined by temperature, salinity, and pressure, J. Mar. Res., 30, 227-255.

Warner, M. J., J. L. Bullister, D. P. Wisegarver, R. H. Gammon, and R. F. Weiss (1996), Basin-wide distributions of chlorofluorocarbons CFC-11 and CFC-12 in the North Pacific: 1985-1989, J. Geophys. Res., 101, 20,525-20,542, doi:10.1029/96JC01849.

Watanabe, Y. W., K. Horada, and K. Ishikawa (1994), Chlorofluorocarbons in the central North Pacific and southward spreading time of North Pacific intermediate water, J. Geophys. Res., 99, 25,195-25,213, doi:10.1029/94JC01884.

Weller, R. A. (1991), Overview of the frontal air-sea interaction experiment (FASINEX): A study of air-sea interaction in a region of strong oceanic gradients, J. Geophys. Res., 96, 8501-8516, doi:10.1029/90JC01868.

White, W. B., K. Hasunuma, and H. Solomon (1978), Large-scale seasonal and secular variability of the subtropical front in the western North Pacific from 1954 to 1974, J. Geophys. Res., 83, 4531-4544, doi:10.1029/ JC083iC09p04531.

Wong, A. P. S., and G. C. Johnson (2003), South Pacific eastern subtropical mode water, J. Phys. Oceanogr., 33, 1493-1509, doi:10.1175/ 1520-0485(2003)033<1493:SPESMW >2.0.CO;2.

Yuan, X., and L. D. Talley (1992), Shallow salinity minima in the North Pacific, J. Phys. Oceanogr., 22, 1302-1316, doi:10.1175/1520-0485(1992) $022<1302: \mathrm{SSMITN}>2.0 . \mathrm{CO} ; 2$

S. T. Cole, Woods Hole Oceanographic Institution, 266 Woods Hole Rd. MS 21, Woods Hole, MA 02543, USA. (scole@whoi.edu)

D. L. Rudnick, Scripps Institution of Oceanography, University of California, San Diego, Mail Code 0213, La Jolla, CA 92093-0213, USA. 